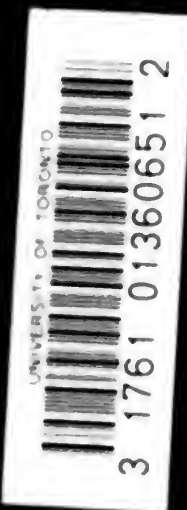

UnIV OF

TORONTO LIBRARY 



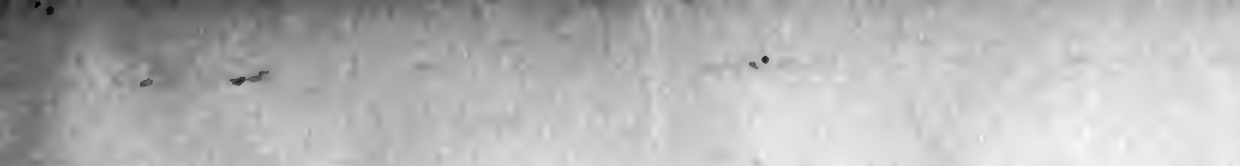

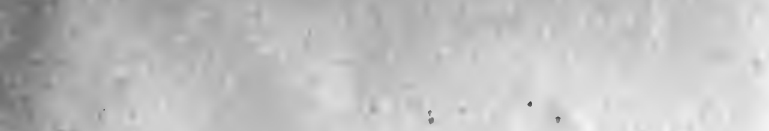

.

?.

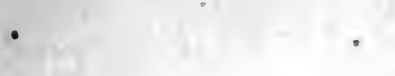

,

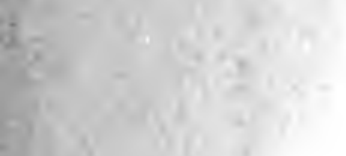

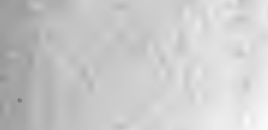

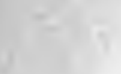

$$
+2-4+4
$$

.

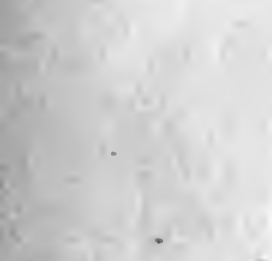

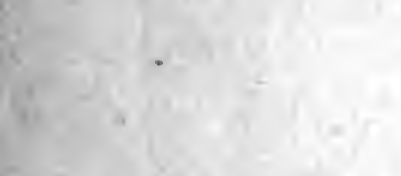

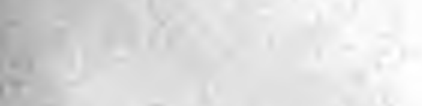

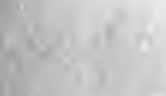

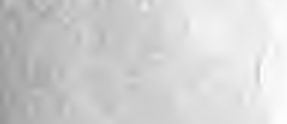

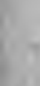

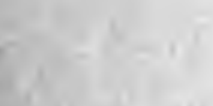

(2)

.
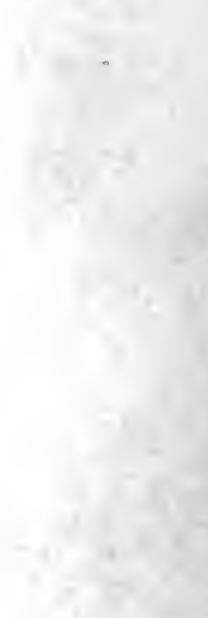
Digitized by the Internet Archive in 2007 with funding from Microsoft Corporation 
1.

$$
9957 / 5
$$


repiented flome

Alumpia Zimiersity otiedies

we histan, oconortucs and public taw, wol.31, pt. 4. 


\title{
ADOLPHE QUETELET
}

As

\section{STATISTICIAN}

\author{
FRANK H. HANKINS, A. B. \\ Sometime University Fellow in Statistica
}

SUBMTTED IN PARTIAL FULFILMENT OF THE REQUTREMENTS

FOR THE DEGREE OF DOCTOR OF PHILOSOPHY

IN THE

Faculty of Poutical Sctevce

Columbia Ustrersity

$$
\begin{gathered}
12.70 .34 \\
4143 .
\end{gathered}
$$

1908 
ELECTRONIC VERSION AVAILACE

No.01000 589 


\section{PREFATORY NOTE}

It is not presumed that the dissertation here presented will add much to the knowledge of Quetelet possessed by those who have read rather extensively in statistical literature. But it is hoped that the increasing number of those who are becoming interested in Quetelet and his work may find these pages useful. The first two chapters give brief sketches of the man, his work and his place in the history of statistics. The last three chapters present what are believed to be the most important of Quetelet's statistical principles. These include the conception of the Average Man as a type, the significance for social science of the regularities found in the moral actions of man, and the theoretical basis of the distribution of group phenomena about their type.

Grateful acknowledgment should here be made to Professor Henry L. Moore for directing me to this stimulating subject, and for continued helpfulness in its pursuit. 


\title{
CONTENTS
}

\author{
CHAPTER I
}

\section{Brograpucal Skztcu}

Parentage-Youthful literary activity-At the University of Ghent; the influence of Garnier-Called to the Athenaeum at BrusselsContributions to mathematics-Educational activity at Brussels; his elementary treatises and characteristics as a teacher-Founding of the Brussels Observatory; sojourn in Paris-Travels in Germany, Italy and Sicily-Research work at the ObservatoryStudies in meteorology and terrestrial physics-His activity in connection with $l$ 'Acadtmie royale de Belgique-Activity as an official statistician-Founding of the Commission centrale de slatistique, of the Statistical Society of London and of the International Statistical Congress-Stroke of apoplexy in $1855-\mathrm{Mem}$. ber of many learned societies-His personality-Home life-The Brussels statue . . . . . . . . . . . . . .

\section{CHAPTER II}

\section{Quetelet in the History of Statistics}

Two lines of development in statistical literature-One of these, the German University "Slatistik," traced through the writings of Muenster, Conring, Achenwall, Von Schlözer and BüschingThe growth of official statistics and the gradual modification of the university discipline-Quetelet's contribution to this change -A second line of statistical development traced through the works of Graunt, Petty and others of the School of Political Arithmetic, Derham, Süssmilch, and the first formulators of mortality tables-The influence of Malthus, Laplace, and especially of J. B. Fourier-Quetelet's contribution to this line of development, treated under (I) population statistics, (II) moral statistics; (III) technique and (IV) application of the normal law of error to the physical measurements of men-Summary . . . .

\section{CHAPTER III}

\section{The Average Mas}

Importance of this concept in Quetelet's writings-Survey of its development-Its generalization in Dw Systime social-Studies to determine the qualities of the average man-Roble of the average man in various sciences-Objections: the average man cannot be constructed as a composite being-The average as the type of 449] 
perfection-Distinction of results obtained in some of Quetelet's studies-The average man as a biological type-The permanence of the type-Quetelet's approach to the doctrine of selection by

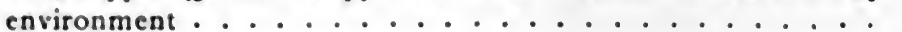

\section{CHAPTER IV}

\section{Moral Statistics}

Introductory-Definition-Quetelet's principal works on moral statistics and his emphasis upon statistical regularities-His explanation of these regularities-The viewpoint of science and its bearing upon the doctrine of free will and upon the explanation of statistical regularities-Explanation of the fluctuations in the numbers from year to year-And of the variations about an averageBecause of the way in which they are formed, the regularities exert no compulsion over the individual-Significance of the regularities for the doctrine of free will-Bearing of statistical inquiry on this doctrine-The statistical regularities and social laws-The difficulty of establishing quantitative relations between social events and their conditions-The effect of the dynamic character of social life upon statistical regularities and their laws-Two basic principles of method in moral statistics-And their importance for the quantitative study of social phenomena . . . . . . .

\section{CHAPTER V \\ Statistical Method}

The basis of statistical method found in the variability of organic and social phenomena about type forms-The probability of an event when all its chances are known-Inductions from experience when the number of chances is unknown-The distribution of chan:es when their number is small-Agreement between theory and experience tested-The distribution of chances when their number is very large-Quetelet's scale of possibility and precision-The derivation of this scale explained-The curve representing the distribution of chances when their number reaches the conceptual limit-Theory provides for extremely improbable combinations, but such are not met with in experience-Quetelet's distinction of "means properly so called" from " arithmetic means"-The theory of the distribution of chances related to the theory of the distribution of errors of measurement and to the distribution of biological measurements-Description of the application of Quetelet's scale to a statistical problem-The probable error-The normal curve only one of many possible forms-The significance of narrowing limits of deviation-Quetelet's classification of causes-Constant causes not revealed by statistical inquiry-Variable causes-Kinds of accidental causes-Causes classified as general and minute-Causes studied by correlation . . 


\section{CHAPTER I}

\section{HIOGRAPHICAL SKETCH}

It might be set down as a rule of mental conduct that, when we become interested in the achievements of a great man, we desire a more intimate acquaintance with his personality and with the routine of his daily life. The deeds of statesmen and warriors are readily appreciated by the generality of men. This is due, not only to their conspicuousness and to the glamour and fascination attending those who achieve notable success in the world of affairs, but to the immediate responsiveness of human emotions to the heroic. But not inirequently does it happen that many years are required for the most important contributions to knowledge to become the possession of an extended and appreciative group of initiated disciples. Herein is found the reason for this brief sketch of Adolphe Quetelet.' Not that his scientific achievements have been passed by with little or no comment, but that there is to-day a rapidly widening group

'Quetelet's name is sometimes accented-Quételet. There is, however, abundant reason for omitting the accent. In the Nouveas M/tmoires, the Bulletins and the Anwwaire of the Brussels Academy, in the Annales and the Annwaire of the Brussels Observatory, and in a num. ber of his works brought out at Brussels, the name is uniformly unaccented. When it is recalled that Quetelet was Secretary of the Academy for forty years and Director of the Observatory for even a longer term. it seems certain that he himself did not accent his name. Morcover in places where he has signed his name it is not accented. The accented spellings seem to be due to Paris publishers. 
of scholars who appreciate the distinctive merit of his development of statistical methods of research. It is believed that such will be interested in a brief account of the man himself."

Born on the twenty-second of February, 1796, in the ancient and historic town of Ghent, Quetelet grew up there amid the stirring scenes which marked the fall of the old regime and the rise of the empire of the brilliant and ambitious Napoleon. Little is known of his parents. No mention is anywhere made of his mother except that her maiden name was Anne-Françoise Vandevelde. His father, François-Augustin-Jacques-Henri Quetelet, is known to have been born at $\mathrm{Ham}$, in Picardy, in 1756 . Being of a somewhat adventurous spirit, François crossed the English Channel at an early age and is said to have become an English citizen. He soon became secretary to a Scotch nobleman, with whom he spent several years traveling on the Continent and sojourning in Italy. He then settled permanently at Ghent, about 1787 . Here he was at length elevated to the position of a municipal officer, in which capacity he rendered valuable and well-

'The chief source for this sketch is the "Essai sur la vie et les ouvrages de Quetelet," by Edward Mailly, one of Quetelet's students and his assistant for thirty-seven years, in the Annuaire de l'acadimie royale des sciences, des lettres et des beaux-arts de Belgique (Brussels, 1875), vol. xli, pp. 109-297. In addition should be mentioned the following: (1) Naúm Reichesberg, “Der berühmte Statistiker, Adolphe Quetelet, scin Leben und sein Wirken," Zeilschrift für schweizerische Statistik (Berne, 1893), Jahrg. xxxii, pp. 418-460; (2) the "Discours" pronounced at Quetelet's funeral, Bullctins de l'acadtmie royale des sciences, des lellres et des beaux-arts de Belgique (Brussels, 1874), Second Series, vol. xxxvii, pp. 244-2t6; (3) Mailly, "Notice sur Adolphe Quetelet," ibid., vol. xxxviii, pp. 8:6-844; (4) Wolowski, " Eloge de Quetelet," Journal de la societe de statistique de Paris $(18 ; 4)$, vol. $x v$, pp. 118-126. Other less important references will be found in the notes. 
esteemed services. He died in 1803 , when Adolphe was but a boy of seven.

It was thus that, upon his graduation from the Lyceum at Ghent, young Quetelet was compelled, at the age of seventeen, to turn his talents to good account. He spent the next year as teacher of mathematics in a private school at Audenaerde." On his nineteenth birthday he was chosen instructor in mathematics at the newly organized college in his native city.

The time between his election and the opening of the University in October, 1817 , seems to have been spent largely in literary composition. In collaboration with G. Dandelin, a former student at the Lyceum, he prepared the libretto for an opera "en un acte, en prose et à grand spectacle," entitled Jean Second ou Charles Quint dans les murs de Gand. This was successfully presented at Ghent, and led to the partial construction of two more dramas by the same authors. Quetelet published quite a number of poems," and until the age of thirty he continued to exercise his poetical talents as pastime and relief from his scientific studies. His poems were of a serious tone, but were well received by both public and critics. We may mention here an Essai sur la romance. which Quetelet brought out in 1823 . In this, from a survey of romance among different peoples, he found the origin of romance in the days of chivalry. This essay, together with translations, in prose and in verse, of German, English, Italian and Spanish romances, shows Quetelet's wide acquaintance at that early age with the

'One of his students here was M. Liedts, who afterwards, as minister of the interior, authorized the Commission centrale de la statistigue.

'Chiefly in the Annales belgigwes and Eludes el lepons franseises de lilltrature ef de morale. Mailly, Essai, pp. 114-131, quotes at length from these poems. 
various European literatures. Mailly, who must be viewed as a friendly critic, believes the Essai sur la romance and many of the poems deserving of republication.

During the three years of his service at the College of Ghent the most important influence brought to bear upon him was that of Jean Guillaume Garnier, ${ }^{3}$ professor of astronomy and higher mathematics. This expert mathematician and refined scholar was called from Paris to the University of Ghent by the King of the Low Countries in 1817 . His influence over Quetelet's eager, youthful spirit was quite decisive. Quetelet says of him,

Little by little his conversation, always instructive and animated, gave a special direction to my tastes, which would have led me by preference towards letters. I resolved to complete my scientific studies and followed the courses in advanced mathematics given by $M$. Garnier. It was at the same time agreed by us that, in order to relieve him in his work, I should give some of the other courses with which he was charged. I thus found myself his pupil and his colleague.

The aspiring dramatist soon found a favorite occupation in the reading of Pascal.

Quetelet was the first to receive the degree of doctor of science from the new university. His dissertation was an original contribution of much importance to the

'1766-1840. He was examiner at l'Ecole polytechnique, 1795-1800; adjunct professor with Lagrange at the same place, 1800-1802; one of Poisson's instructors and an intimate of J. B. Fourier. See Nouvelle biographie génerale (Paris, 1858), vol. xix, also “ Notice sur J. G. Garnier," by Quetelet, in the Annuaire de l'académie royale de Bruxelles (1841), vol. 7; and sketch by Quetelet in Sciences mathematigues et physigues au commencement du xixe sizcle (Brussels, 1867).

" Notice sur J. G. Garnier," Annuaire de l'acad. roy. de Brux. (1841), vol. vii, pp. 200-201. 
theory of conic sections: it demonstrated two new propositions, one of which developed the properties of a new curve, the "focale." " In October of this same year (1819) he was called to the chair of elementary mathematics in the Athenaeum at Brussels. Repairing thither at once, he was soon in the midst of a learned circle of Belgian and French scholars. Among the former may be mentioned the old Commandeur de Nieuport, the only Belgian scientist then known abroad, and the Baron de Reiffenberg. The French savants were refugees enjoying the hospitality of the tolerant Pays-Bas. Quetelet's intimacy with them, no doubt, helped to fix his political views and, in particular, to accentuate his leanings toward liberalism. They were a distinguished company, including such men as the poet Arnault, the artist David, the naturalist and traveler Bory de Saint-Vincent and the statesman and jurist Merlin de Douai.

In February, I820, Quetelet was elected to membership in the Academie royale des sciences et belles-lettres de Bruxelles. The meetings of the Academy, at this time, were attended by scarce half a dozen Belgian scholars:" interest in it had almost ceased. Quetelet was soon to become its moving spirit, to arouse it to renewed activity and to make it the inspiration of a new intellectual awakening throughout Belgium. His first year in the

'The discovery of this curve was hailed as a brilliant achievement by his contemporaries. From Reichesberg's essay " Der berühmte Statistiker, etc.." p. 422, we learn that Raoul, a colleague of Garnier's and like him a Parisian and a mathematician, compared this discuvery to that of Pascal's cycloid, saying that this alone sufficed to place Quetelet's name alongside that of the great geometrician. See also Mailly. Essai, pp. I1s and 150.

'Among these were the pharmacist Kickx, the chemist Van Mons, and Quetelet's teacher and friend, Garnier. " who strongly urged the election of his favorite pupil." Mailly. Essai, p. 135. 
Academy was marked by the presentation of two mathematical memoirs, the second of which, Nouvelle théorie des sections coniques considérées dans le solide, brought him much honor.

During the next nine years, or until 1829, Quetelet devoted much attention to mathematics. Physics also interested him at this time.' His memoirs on these subjects, published in the Nouveau mémoires of the Brussels Academy, and the Correspondance were both numerous and meritorious." "The mere enumeration of his contributions to pure and mixed mathematics would occupy a very large space, and from their intrinsic merit, patient and conscientious research and earnest regard for truth, would alone have secured him a foremost place among the distinguished and scientific men of the present century." 3

During this period appeared the first volumes of the Correspondance mathématique et physique, "with Quetelet and Garnier as joint editors. Beginning with the third volume Quetelet alone was editor. Leading mathematicians and scientists of all Europe, and particularly of England, France, Germany and Holland, were contributors. ${ }^{5}$ In this manner Quetelet came into touch

'For the flattering reception given one of his memoirs on caustics, see Revue encyclopedique, Sept., 1825, vol. xxvii, pp. 794-795.

"A general survey of them is given by Mailly, Essai, pp. 131-154.

${ }^{3}$ F. J. Mouat, "Monsieur Quetelet," Journal of the Statistical Society of London (1875), vol. xxxvii, p. 114.

'Eleven vols.: vols. $\mathrm{i}$ and $\mathrm{ii}$ at Ghent, the others at Brussels. Vols. i-เi, 1825-1830; vols. vii-viii (not located); vols. ix-x-xi, 1837, 1838, 1839.

'Among these were Herschel, Babbage, Wheatstone, Whewell, Chasles, Villermé, Ampère, Bouvard, Hachette, Gautier, Gauss, Hansteen, Olbers, De la Rive, Wartmann, Encke, Brandes and Hansen. Quetelet has given an account of the Correspondance in his Premier sizcle de l'academie royale de Bruxelles (Brussels, 1872), pp. 36, et seg. 
with the foremost scholars of his time. The Correspondance covered every branch of mathematics, as well as mechanics, astronomy, physics, meteorology and statistics.' The character of the contributions made this journal, for a time, the foremost of its kind in Europe." Its place was gradually taken by numerous publications at home and abroad covering the special fields more intensively.

But the chief work of Quetelet during these first years at Brussels was educational. We have seen that he came to the city in 1820 as professor of elementary mathematics at the Athenaeum. Four years later he succeeded M. Thiry in the chair of higher mathematics in this institution, ' and at the same time began giving popular courses in geometry, probabilities, ${ }^{4}$ physics and astronomy at the Museum, Brussels. The success of these popular lectures was so marked that, after two years, the Muséc des sciences et des lettres was organized, by royal decree. on the basis of a plan drawn up by Quetelet. In this institution he began giving a course on the history of

'Numerous references in these volumes show Quetelet's early familiarity with past and current statistical development. As an instance of the influence of Jean-Baptiste Fourier, we find in a note, vol. ii, p. 177. one of Quetelet's frequent references to Fourier's statement that. ". Statistics will make progress only as it is retained in the hands of those versed in higher mathematics." The first six volumes only (I have not seen volumes vii and viii) have statistical articles from Quetelet.

-Von John, Geschichte der Statistik (Stuttgart, 1884), p. 334.

- Meanwhile he had spent three momentous months in Paris, where he met Laplace and others, who profoundly influenced his thought. See p. 20, infra.

- His first course of instruction in probabilities was given in the echolastic year 1824-5 at the Athenacum; this was the year immediately following his sojourn in Paris; the next year $(1825-6)$ be gave an introductory course at the Museum. 
the sciences." The following very characteristic statement, which he often referred to afterwards, was made at the opening of this course :

The more advanced the sciences have become, the more they have tended to enter the domain of mathematics, which is a sort of center towards which they converge. We can judge of the perfection to which a science has come by the facility, more or less great, with which it may be approached by calculation."

He continued his courses on physics and astronomy at the Athenxum until 1828 , when he resigned on account of his appointment as astronomer at the observatory. But his lectures at the Musée des sciences et des lettres ${ }^{3}$ were maintained until the absorption of the Musée by the Universite libre in 1834 . But he was not allowed to remain long free from professional duties. Two years later $(1836)$ he was made professor of astronomy and geodesy at the newly erected Ecole militaire at Brussels.

For his courses at the Musée he prepared a number of elementary treatises which, on account of their clearness and exactness, obtained well-merited popularity. The first of these, Astronomie élémentaire ${ }^{4}$ was soon followed

'This course bore fruit in the publication by him of "Aperçu de l'état actuel des sciences mathé matiques, chez les Belges," prepared at the request of the British Associat ion and published in Report of the British Association for the Advancement of Science, vol. v (1835), pp. 35-36 and in Correspondance, vol. ix, pp. 1-47; Histoire des sciences mathematiques et physiques chez les Belges (Brussels, 1864), and Sciences mathematiques et physiques chez les Belges, au commencement du xixe sizcle (Brussels, 1866).

"Mailly, Essai, p. 159; found also in "Conclusions" of Instructions populaires sur le calcul des probabilites, p. 230.

${ }^{3}$ These lectures after 1828 were in astronomy and physics.

'Paris, 1826. 
by the Trailt populaire d'astronomie,' a work of unusual merit. It was often reprinted in France and Belgium and was translated into several languages. Houzeau* says it was of almost epoch-making importance for the spread of the knowledge of astronomy; for, in addition to the wide circle of general readers whom it reached, it opened the way for popular instruction in the science of astronomy. It attained the distinction of being placed on the Index librorum prohibitorum by the Catholic Church, a fact which hastened and augmented its wide influence. About the same time he published his Positions de physique ou rtsume d' un cours de physique gentrale,' which was translated into English by Robert Wallace." The translator says in his preface, "No other work in the English language contains such an extensive and succinct account of the different branches of physics or exhibits such a general knowledge of the whole field in so small a compass."

Among these treatises, besides the De la chaleur.s was the Instructions populaires sur le calcul des probabilitks," which, Quetelet says, is "a resumé of lectures given at the Musee as an introduction to my courses in physics and astronomy." It bears on the title-page the significant aphorism Mundum numeri regunl. We meet in the preface several distinctly typical thoughts. Thus,

'Paris, 1827. 'Reichesberg, "Der berühmte Statistiker," p. 433.

'Three volumes, Paris, 1826.

- Facts, Laws and Phenomena of Nalural Philusophy, or a Swomomary of a Course in General Physics (Glasgow, 1835).

- Brussels (?). 1832.

- Brussels, 1828, 236pp. English translation by R. Beamish, London. 1839.

'Preface, p. 1. These courses and this book are of later date than his trip to Paris from Dec.. 1823, to Feb.. 1824. See p. 19. et sey. infre. 
he says, "It has seemed to me that the theory (calcul) of probabilities ought to serve as the basis for the study of all the sciences, and particularly of the sciences of observation." "Since absolute certainty is impossible, and we can speak only of the probability of the fulfillment of a scientific expectation, a study of this theory should be a part of every man's education." The book is intended for the general reader, and the only prerequisite is a knowledge of the rules of arithmetic. In a most perspicuous manner he expounds the fundamental propositions of probabilities, Bernoulli's principle of agreement between experience and calculation, precision, the principle of least squares, the construction of a mortality table for a stationary population, and the calculation of probable and of average life. We cannot forbear another quotation :

Chance, that mysterious, much abused word, should be considered only a veil for our ignorance; it is a phantom which exercises the most absolute empire over the common mind, accustomed to consider events only as isolated, but which is reduced to naught before the philosopher, whose eye embraces a long series of events and whose penetration is not led astray by variations, which disappear when he gives himself sufficient perspective to seize the laws of nature.'

As a teacher and lecturer Quetelet was very successful. He was considerate and amiable, free from pedantry and conceit, and "endowed with a true talent for exposition." " His courses at the Museum attracted a great number of auditors from all ranks of society. Several of his pupils at the Athenaeum afterwards became distin-

".C Conclusion," p. 230; sec also p. 8.

'Mailly, Essai, p. 156. 
guished. Joseph Plateau, probably the most eminent of these, in dedicating to Quetelet his greatest work. Statique experimentale, etc., says: '

Vous, qui avez été l' un des actiis promoteurs de la régénération intellectuelle de la Belgique, et dont les travaux ont tant contribué à l'illustration de ce pays; vous, qui a vez guidé mes premiers pas dans la carrière des sciences, et qui $\mathrm{m}^{\prime}$ avez appris, par votre example, à exciter chez les jeunes gens l'amour des recherches; vous, enfin, qui n'avez cessé d'étre pour moi un ami devoué, elc.

Quetelet is said to have taken an almost paternal interest in those of his students who showed special aptitude. He entertained them and opened to them freely the rich treasures of his own learning.

During these years of educational activity, an important series of events had taken place. Soon after his election to the Academy (r820) Quetelet began arousing interest in favor of an astronomical ouservatory. He made friends for the project on every hand, secured resolutions from the learned societies of Belgium and personally won the support of the minister of public instruction, M. Falck. Quetelet himself, having no experience with the methods and instruments of practical astronomy, was sent to Paris in December, 1823. at the expense of the state. He was kindly received at the Paris observatory by Arago and Bouvard, the latter of whom took special interest in instructing him in the knowledge of practical astronomy.

'Bulletins de l'aced., and series, vol. xxxvii. pp. 253-254. note.

'Wolowski, " Floge de Quetelet." Jowrnal de la socille de stasistipur de Paris, vol. Xv, p. 122.

'For Quetelet's very interesting account of his introduction at the observatory at Paris, see " Notice biographique de M. Bouvard," Anwwaire of the Brussels Academy (1844), vol. X. pp. 112-113. 
Bouvard also introduced him to an inner circle of friends. Among these were Laplace, Poisson, Alexander von Humboldt and Fresnel. It is probable that Quetelet at this time formed the acquaintance of Fourier, from whom he received some instruction.' During his three months' " study in Paris, doubtless the most significant influence on the direction and character of his thought was that exerted by the immortal Laplace. Under this great mathematician, Quetelet received instruction in the theory of probabilities. ${ }^{3}$ This course must have exerted a profound influence on Quetelet's scientific and philosophical views. The emphasis which Quetelet laid upon the principles of probabilities in his courses at the Museum during the years immediately following this sojourn in Paris has already been noted. ${ }^{4}$ Quetelet's

'In the Physique sociale (Paris, 1869), vol. ii, notes, p. 446, Quetelet says, "During a temporary sojourn at Paris, about a half century ago, I had the honor of the kindly friendship of M. Bouvard, who was pleased to present me to the illustrious author of the Mecanique celeste, of which he was the collaborator for a part of the calculations and cbservations. I had the good fortune then of being able to prcfit by the counsel of this great geometrician and to win the fricndship of several of the most distinguished scholars of France, who ordinarily grouped themselves about him. Later Jean-Bapt. Fourier, ... was pleased also to express to me sentiments of kindness .. . I had the good fortune of enjoying the lessons of these two great masters and I still remember with gratitude the encouragement which they were pleased to give me."

"Von John, Geschichte der Statistik, p. 333, says two years, but this is undoubtedly wrong. Quetelet himself says, "I arrived at Paris towards the end of 1823 " and "I returned to Belgium in 1824 ," in sketch of Bouvard, Sciences mathématiques et physiques au commencement du xix sizcle, pp. 611-614; Mailly, Essai. p. 172, says that Quetelet returned to Brussels at the beginning of 1824 , and that on the first of March he addressed the Academy on the establishment of an observatory.

'See Reichesberg, “ Der berühmte Statistiker," p. 450.

'Pp. 15 and 17, supra. 
writings previous to this time, show none of that emphasis on the importance of probabilities in scientific researches, which from this time on becomes more and more prominent. It would seem, therefore, that this contact with Laplace, and with others holding like views, implanted in Quetelet's mind the germs of those thoughts which afterwards developed into his conception of the social system and his methods of investigating its laws.

After his return to Brussels, the project of an observatory was advanced, but with discouraging slowness. In 1827 Quetelet was charged by the King with making the first purchase of instruments. In company with his longtime friend, Dandelin, he repaired to London. After attending to business matters, he spent a couple of months in visiting the universities, observatories and learned societies of England, Scotland and Ireland.' The following January he was named astronomer of the Royal Observatory at Brussels. However, delays in construction, due to differences between the city and national governments as to financial support and to the revolution of 1830 , prevented his occupying the Observatory until 1832.

Meanwhile he traveled. From July to October, 1829, accompanied by his accomplished wife," he made a tour through Holland and Germany. He visited numerous astronomers and men of science, inspected the chief observatories and made himself familiar with the state of astronomical science in Germany. One of the most memorable incidents of this eventful journey was Quetelet's visit with the great Goethe at Weimar. Here he

'.. Description des plusieurs observatoires d'Angleterre," Corres. pondance, vols. iv and v.

He had been married in 1825 to the daughter of the French physician and refugee, M. Curtet, who was also a niece of the chemist Van Mons. 
spent eight days, at the time of Goethe's eighticth birthday, discussing, among many things, the latter's optical theories. This afforded the greatest pleasure to Goethe, as well as to Quetelet and his wife, and led to an unusually felicitous correspondence.'

The following summer he made a four months' tour through Italy and Sicily, making the acquaintance of scholars and learned societies. On this trip, as also on the preceding, he made numerous observations on the strength of terrestrial magnetic currents. ${ }^{2}$

After his installation at the Observatory, in 1832 , his life for the next forty-two years was devoted almost entirely to three major interests: the various lines of research carried on at the Observatory, the work of the Academy and his statistical inquiries. These three spheres of activity will be treated separately.

At the Observatory a vast amount of research work was organized, dealing with astronomy, meteorology and physics of the globe. ${ }^{3}$ Quetelet had always been interested in falling stars. In his doctor's dissertation he had defended Olbers's theory of the lunar origin of aeroliths. As early as 1826 he developed a method for

:Quetelet has given two accounts of the sojourn at Weimar: "Notes extraites d'un voyage scientifique, fait en Allemagne pendant l'été de 1829," in the Correspondance, vol. vii, pp. 126-148, 161-178 and 225-239. and "Johann Wolfgang Gocthe," in Sciences math. et phys. chez les Belges au commencement du xixe siecle, pp. 656-669. There is another account, "Quetelet bei Goethe," in Festgabe für Johannes Conrad (Jena, I898), pp. 311-334.

'Results published in Nouveaux memoires, vol. vi, and Correspondance, vol. vi. He made a three months' trip through Italy and Tyrol beginning in August, 1839, at which time he gathered another series of magnetic observations.

'At the Observatory Quetelet had almost from the beginning two assistants, one of whom was Edward Mailly, the author of the Essar which has been the chicf source for this sketch. 
calculating the height of a meteor from two observations.' This plan, being well received, enabled Quetelet to organize simultaneous observations in four Belgian cities. At this time we find him emphasizing what must be considered one of his most important contributions to the various fields of science in which he labored, namely, the necessity of simultaneous observations at different points. His introduction of it here into astronomical research was followed, as we shall see, by his development of it on a large scale in meteorological and physical research and by his efforts to secure uniform international statistics. At the same time he emphasized the necessity of correcting astronomical observations for the personal equation in order to render them comparable. In 1836 his observations of falling stars led to the discovery that the nights of August ten and eleven, like those of November thirteen and fourteen, were conspicuous for meteoric showers.

Among other facts connected with his astronomical activity, we may note a series of observations of sunspots, begun in 1832; observations on tides on the coast of Belgium, undertaken at the request of Whewell in 1835 ; the commencement, the same year, upon the initiative of Sir John Herschel, of hourly meteorological observations at the time of the solstices and equinoxes, but, after 1841, made every two hours throughout the year; magnetic observations, begun in 1840 at the request of the Royal Astronomical Society of Lonc.on, and made at five-minute intervals during one twenty-four hours each month; the erection from 1838 to 1839 , at government request, of small telescopes in the five largest cities out-

'See Correspoindance, vol. i. also Refurt of the Erilish Association for the Advancement of Srience. 1833, p. \$89: 1835, p. xxxviii. 
side of Brussels, and of sundials in forty-one towns, in order to guarantee uniformity of time throughout the kingdom; and the determination of the difference in longitude between Greenwich and Brussels. The publication of the Annuaire and of the Annales of the Observatory began in 1834 . In 1854 a volume entitled Almanach seculaire was issued from the Observatory. After 1857 the work of the Observatory was carried on largely by Quetelet's only son, Ernest, who became an accomplished astronomer and his father's successor as director.

But Quetelet's dominant scientific interest seems to have been other than strictly astronomical. The study of meteorological and physical phenomena, especially their periodicity, absorbed much of his attention. These observations began with the temperature of the earth,' and the intensity of atmospheric electricity and were extended to include the variations of barometric pressure and periodic phenomena of the life of plants and animals. His study of atmospheric electricity and its annual and diurnal variations, established the law of the variation of intensity with height. This study was looked upon as of considerable importance by French, German and English scientists. ${ }^{3}$ Wheatstone and Faraday made it the subject of special reports to the British Association and the Royal Society respectively. ${ }^{4}$

'Suggested by Fourier's MEnoire sur les temperatures du globe terrestre et des espaces planktaires (Paris, 1827).

${ }^{2}$ Many of these studies, first published in the Annales of the Observatory and in the MEmoires of the Academy were brought together in Sur le climat de la Belgique (2 vols., 1849-1857).

'See Archives des sciences physiques et naturelles (Geneva, July. 1849).

'See Report of the British Association (1849), vol. 19. "Transactions of the Sections," pp. 11-15. 
More important by far were the observations of barometric pressures leading to the discovery of atmospheric waves.' He had conceived the advantage of simultaneous observations in various places in dealing with matters of climatology. Securing the assistance of scientists throughout Belgium, and later throughout Europe, he secured a mass of observations of hourly barometric pressures. When these were chartered they revealed the succession of variations in pressure due to atmospheric waves. This study ${ }^{\circ}$ of the form, size and velocity of atmospheric waves was pioneer. When carried out on the basis of simultancous international observations, this discovery led to most important consequences for our knowledge of storms and probable weather conditions. ${ }^{3}$ A long stride was made toward international coöperation and uniformity by the Sea Conference, held at Brussels in $18533^{\circ}$ Ten states were represented and Quetelet was chosen president. Further advance was made in 1873 at the first International Meteorological Congress, s an assemblage Quetelet had long desired to call. He was represented by his son, and his plan for the observation of natural phenomena was made the central theme of discussion.

'He was probably led to such research by the suggestion of Sir John Herschel. But Quetelet organized independently fire stations in Belgium and later seventy scattered over central and western Europe. whose observations were forwarded and tabulated at the Brussels Observatory. See Bulletins de l'aced., and Series, vol. xxxviii, p. 838.

- Published in the Annales of the Observatory, vol. viii, part 1 .

'See quotation. Mailly's Essai. p. 253, from the Annwaire de la socilts mbleorologigue de France, 1867.

- The suggestion for this conference came from Matthew Maury, of Washington. At his suggestion Quetelet induced the Belgian government to call the conference. " to establish a uniform system of meteorological observations for the sea." Mailly, Essai, p. 224.

-At the World's Exposition at Vienna. 
In close connection with these observations were those made on the periodic, annual and diurnal, phenomena of plants and animals. These had been begun in 1839 by a study of the time of blooming of flowers, and were extended in 1841 to include the time of foliation and of falling leaves. In this work, leading to many interesting and significant correlations, he enlisted the coöperation of scientists in every country of western Europe. For this purpose, Quetelet prepared in 1842 an extensive scheme of investigation ' embracing meteorology, physics of the globe, and the annual and diurnal habits of plants and animals. ${ }^{2}$

De la Rive, in reviewing Sur la physique du globe, ${ }^{3}$ attributed the highest importance to these studies in meteorological and terrestrial physics, placing Quetelet in the "first rank among meteorologists." " Reichesberg remarks that there are few physicists who have advanced the development of meteorology and physics of the globe to such an extent as Quetelet.s The great merit of these studies is found in the admirable plan for the study of periodic phenomena, particularly in the continued insistence on the simultaneous observation of the same phenomena from many scattered points. He was the first to collect material in such manner and quantity as made possible the discovery of regularity where the human

'For this plan see Bulletins de l'acad., ist Series, vol. ix, part I, pp. 65-95.

'Results published annually in Nouveaux memoires of the Academy beginning with vol. $x v$.

"Publisheci in the Annales of the Observatory (186r), vol. xiii; also separately Brussels, $186 \mathrm{x}$.

-Archizes des sciences physiques et naturelles (Geneva, 1862, vol. xv. July).

3. Der berühmte Statistiker." p. 442. 
mind had previously found only chance. The wonderiul scientific imagination of the man is strikingly shown in his conception of a world physics as presented in his Sur la physigue du globe and his Mtiborologie de la Belgrigue comparke a celle du globe.' Here was a vast conception, embracing in its realization the most cor:3plete observations of the magnetic, meteorological, animal and vegetable phenomena of the entire earth on a systematic and uniform basis with a view to discovering the order in a vast mass of apparently disordered events.

We take up now Quetelet's connection with the Academy. Chosen to membership in 1820 , he soon came to play a leading röle in its activities. He was named director for the years 1832 and 1833 , and was chosen perpetual secretary in 1834 . This office he held for forty years, during which he was the "guiding spirit" of the Academy. "He so ruled his little republic as to secure the regard, esteem and veneration of all within its walls, ..."3 At his suggestion, the Academy began the publication of its Bulletin in 1832 , and three years later, as secretary, he brought out the first volume of the $A n$ mwaire. When the Academy was reorganized in $1845 .^{\circ}$ Quetelet secured the addition of the class of BeauxArts. ' This he had attempted in 1832 . Having failed

' Brussels, 1867.

'Mouat, "Monsieur Quetelet," Jowr. Slat. Soc. of London, vol. xxxvii, p. 114; see also "Discours," pronounced at Quetelet's funeral. Bulletins de l'acad., and Series, vol. xxxvii, p. 249.

- Mourat, loc. cil.

-It was known as "l'Académic royale des sciences et belles-lettres de Bruxelles" until 1845, and since then as "I'Académie royale des sciences, des lettres, et des beaux-arts de Belgique."

'He scems to have had a natural and decided taste for art. He first eame into public notice as a youth through the exhibition of the prize drawing at the Lyceum at Ghent in 1812 . 
he contented himself with assisting in the organization of the Cercle artistique et litteraire, of which he was for some time the presiclent. As secretary of the Academy he was always prompt and painstaking in fulfilling his duties. Fifteen days before his death, though already suffering from his death malady, he attended the session. "In his appreciations of the works of his fellows, he was usually fair-minded, but superficial." Many of his own articles were first published by the Academy, and it was largely through the medium of the Academy that Quetelet became the stimulator of a new intellectual life in Belgium. There are many testimonials to his stimulating influence. He was declared, at his death, to be virtually the creator of the Academy, as also of the Observatory and other scientific and educational institutions, all potent in the intellectual regeneration of Belgium. ${ }^{2}$

But, though Quetelet's influence in and through the Academy and his researches in meteorology and terrestrial physics are of importance, he became known to the world through, and will be remembered chiefly for, his statistical studies. After 1825 his articles dealing with every phase of statistics became more and more prominent among his various publications. Since these writings are to be studied in some detail in later chapters, we will give here a sketch only of his practical activity with reference to official statistics.

Upon the formation of the statistical bureau of Holland under Smits, in 1826, Quetelet became correspondent for Brabant. He at once urged that a census be taken and assisted in formulating plans for the census of 1829. The results of this census were published

'Mailly, Essai, p. 261 .

'See "Discours," pronounced at his funcral, Bulletins of the Acadcmy, and series, vol. xxxvii, pp. 244-266. 
separately in each country after the revolution of $1830 .{ }^{\prime}$ He later became supervisor of statistics in the administration, and in 1841 he was instrumental in the organization of the Commission centrale de statistigue. This Commission, of which he was president until his death, supervised the subsequent censuses, organized the work of the provincial commissions, and brought the Belgian statistics to a standard of completeness and reliability that was pre-eminent. Wolowski said, in 1874, that "the success of the Commission, thanks to Quetelet. was so great that many nations . . . hastened to found a central commission of statistics patterned after that which he had founded." "

Meanwhile, as official Belgian delegate to the meeting of the British Association at Cambridge, in 1833, he had been the immediate cause of the formation of a statistical section.3 This section was put in charge of a permanent committee, having Babbage as chairman and Quetelet as one of its members. Quetelet considered the scope of this section too narrowly limited by the rules of the Association. "He accordingly suggested to M. Babbage, from whom we have the statement, the formation of a statistical society in London." " This society was

'Recherches sur la reproduction et le morlalite de l' homme au.x differents ages, et sur la population Belgigae (premier recueil officiel) par MN. Qwetelet et Simits (Brussels, 1832).

". Eloge de Quetelet," Jowr. de la soc. de sta. de Paris, vol. xv. p. 120.

'See Report of the British Association, 1833. p. 484; also Quetelet, " Notes extraites d'un voyage en Angleterre en $1 R_{33}$." Correspondance. vol. viii.

'F. J. Mouat, "History of the Statistical Society of London," Jowr. Sla. Soc. of London, Jubilee vol., Pp. 14-15. See also in the same Jowrnal. vol. i, p. 4; vol. xxxiv, p. 412, and vol. xxxvii, pp. 309 and 415; and F. X. Neumann-Spallart, "Apergu historique," in the Bulletin de 1 '/mstilut international de statistique. vol. i, pp. 1-2. 
founded March 15, 1834, and the same year Quetelet was elected a corresponding member of the British Association.

The need of international uniformity and comparability of statistical data impressed itself deeply upon Quetelet, as had the similar need with respect to astronomical and meteorological data at an earlier date.' With characteristic zeal he sought to bring about the practical realization of this highly important end. The idea of international coöperation, bearing the approval of the Commission centrale, was presented to a group of scientists at the Universal Exposition at London in 1851 . The project met with heartiest approval. Brussels was designated as the place of meeting for the first session because of the excellence of the Belgian statistics. Further proceedings devolved on the Commission centrale. A committee was chosen to draw a plan of organization, prepare rules of order and propose questions. As chairman of this committee, Quetelet became the moving and directing force in what followed. The government was induced to issue invitations to an International Statistical Congress, plans of organization were drawn providing for three sections, and a set of eleven questions was proposed for discussion. At the first session of the Congress, Brussels, 1853, Quetelet was chosen president, and in his opening address he dwelt upon the advantages of international uniformity in plans, purposes and terminiology of the official statistical publications.

The Congress was a decided success and other sessions followed. The influence of this Congress on both the theory and practice of statistics was immense. Meitzen*

'Pp. 23 and 25, supra.

'August Meitzen, Mistory, Theory and Technique of Statistics, tr. by Roland P. Falkner, Supplement to Annals of the American Academy of Political and Social Science (March, 1891), p. 81. 
says, "Everything which has occurred for statistics" since the beginning of the Congress has been essentially a consequence of its stimulating and invigorating influence." Ficher, in opening the Statistische Monalschrift" with a sketch of Quetelet, says "International Statistics will ever remain Quetelet's most splendid creation." Quetelet was a prominent figure at all but two sessions of the Congress: ${ }^{3}$ Wolowski tells us that " it was always the spirit of Quetelet that animated them." We see him at the age of seventy-six, upon urgent request, repairing to St. Petersburg to the last but one of these sessions. And we see him returning, refreshed and rejuvenated by the splendid ovation he had received.' This was. one of his greatest triumphs and was to him a source of deepest gratification.

Before closing this sketch, mention should be made of an attack of apoplexy from which Quetelet suffered in the summer of 1855 . He was stricken suddenly while studying on the veranda of his home at the Observatory. He recovered strength in a few weeks to resume his labors, but his intellect had lost its acuteness, his memory its certainty and his literary style much of its beauty and eloquence. His writings, for a long time, needed the most thorough revision. Mailly, who was one of his assistants at this time, tells us that he would use the same word over and over again, and would express the same thoughts with monotonous repetition. He even

'Meitzen must mean official statistics.

'Vienna, 1875, vol. i, p. 13.

'Paris, 1855, and the session after his death, Budapest, 1876.

".. Eloge de Quetelet," Jour. de la sor. de sta. de Paris, vol. xv, p. 120.

'See "Obituary Notice," Jcur. Slat. Sor. of London, vol. xxxvii, p. 115. 
constructed sentences whose ends bore no relation to their beginnings, and, when such were corrected, Quetelet would be unconscious of change.' His books published after 1855 , in so far as new in composition, are full of ambiguous or unintelligible phrases, ill-arranged and very repetitious. This is notably true of his histories of 1864 and $1866,{ }^{2}$ and his works on meteorology, ${ }^{3}$ as well as of some of his statistical writings. His affliction was intensified by the death of his wife and of his only daughter. Yet, in time, he very largely regained his former eagerness of spirit and worked on to the end with unabated intensity and care. In his latest years, further saddened by the loss of some of the younger spirits about him, he became more and more absorbed in his daily labors. He had for so many years guided the work of the Academy and the Observatory, that it is little to wonder at, that they were the burden of his incoherent mumblings in the brief spell of deliriousness preceding his death.

$\mathrm{His}$ life was crowned with honors. He was a member of more than one hundred learned societies, and had been decorated with the badges of many royal and honorable orders of all lands. Among the learned societies were academies of science, institutes, royal societies, and medical, statistical, geograplical, meteorological, anthropological, philosophical, physical and astronomical societies the world over.4 The Academie des sciences morales et

'Mailly, Essai, p. 266, and Reichesberg, "Der berühmte Statistiker," p. 460.

"To those mentioned in note p. 16, supra, should be added Premier siècle de l'académie (Brussels, 1872).

3Among these were: Sur le climat de la Belgique (Brussels, 2 vols., 1849-1857); Phy'sique du globe (ibid., 1861); Méterologie de la Belgique comparke a celle du globe (ibid., 1867).

- Ficher, Statistische Monatschrift, vol. i, p. 13, says that, aside from 
politigues of Paris bestowed upon him its highest honor by electing him an associate in 1872 . At the same time the Academy of Sciences of Berlin hailed him as "the creator of a new science.", Reichesberg observes that as the founder of a new statistics he developed the scientific method by which the laws of social life may be discovered, and thus established the foundation of a new science, Social Physics, as he himself called it, or Sociology, as it is customarily called today.' Doubtless one of Quetelet's greatest merits lies in his development of moral statistics. Of this development two features are of lasting significance. One of these is the development of a method of investigation having a mathematical basis in the theory of probabilities. The other is found in the emphasis on the word moral. Others had studied birth, death and marriage statistics, but Quetelet was the first to perceive in such studies a field that could be expanded to include the whole nature of man and the characteristics of human society. The simple proposition that the moral nature of men and the qualities of a group of men can be best determined by a statistical study of their actions was exalted by him into the foundation of exact social science.

Quetelet's personality is represented as most winning. Modest and generous, convinced but respectifl of others' opinions, always calm and considerate, a man of broad learning and an attractive conversationalist, he won and kept friends wherever he went. A man of excellent tact,

learned societies of Belgium, he was a member of ninety-six in Europe. one in Asia, one in Africa, and nine in North and South America. For a list of these societies see Bulletins de l'acad. ray. de Belg., and series. vol. Xxxvii, pp. 246 and 265 .

'Bull. de l'acad., and series, vol. xxxvii, p. 257.

" Der berühmte Statistiker," pp. 443-444. 
as well as of tremendous enthusiasm, he readily enlisted support for many schemes of coöperative scientific endeavor. A man of wide intellectual interests, and at the same time, endowed with a prodigious capacity for labor, he contributed to the advancement of several sciences, aroused anew the entire intellectual life of his country and stimulated the activity of artists and scientists throughout the world. Until the attack of 1855 , he is represented as always animated and genial, fond of wit and laughter. "Rabelais was almost as dear to him as Pascal."."

His home life was of marked beauty and serenity. He found great pleasure in his two children, and the astronomical ability of his son was a source of great pride to him. Quetelet was himself a modest musician, and his wife an accomplished one. Friends were regularly entertained at dinner on Sundays, and Sunday evenings were usually given over to music and charades. Personally acquainted with the leading scientists of his time, he exercised the most generous hospitality in the home at the Observatory. Distinguished men, coming to Belgium from any of the European capitals or centers of learning, brought letters of introduction to Quetelet and were always assured a gracious reception by him. One of the speakers at his funeral said of him, "as a man of science he was admired; in political affairs he was respected; in private life he was beloved." "

He died on the seventeenth of February, 1874, and was buried with honors fitting one of earth's nobility. His funeral was the occasion of a most numerous and distinguished gathering of members of royal families,

'Mailly, Essai, p. 262.

'Bulletins of the Belgian Academy, 2nd series, vol. xxxvii, p. 261. 
scientists, men of letters and representatives of learned societies. Funds for a statue of him were soon raised by popular subscription, the monument being unveiled at Brussels in 1880 . He is represented seated in an armchair, the fingers of his left hand spread out on a nearby globe; his right arm rests on the arm of the chair and his head is raised as he peers into the secrets of space.'

The extent of Quetelet's scientific activity was so great, covering as it did the various fields of mathematics, astronomy, physics and statistics, that his rank among men of science is difficult to estimate. It may be said without fear of contradiction that few men have so largely contributed to the spread of scientific knowledge or stimulated such wide and persistent discussion and inquiry as did he. One historian says of him, "In the history of natural science, Quetelet will, with good right, be placed in the rank of Pascal, Leibnitz, Bernoulli, Laplace, Poisson and such scientists." .

'Reichesberg. "Der berühmte Statistiker," p. 460.

'Von John, Geschichte der Slatistik, p. 335. 


\section{CHAPTER II}

\section{QUETELET IN THE HISTORY OF STATISTICS}

It is proposed in this chapter to relate Quetelet to the historical development of statistics previous to 1825 , when he began to show some statistical activity. This development can be traced through two series of writings, showing different conceptions and methods. One series includes the works by Muenster, Conring and Achenwall and his disciples; the other, works by Graunt, the School of Political Arithmetic, Derham and Süssmilch. Those of the first series embrace the whole life and organization of the state as their object, and rely on verbal analysis and description. Those of the second are relatively limited in scope and use enumeration and calculation as distinctive methods. The conception, scope and method of each of these two classes of statistical writings will be briefly traced, and Quetelet's contribution to their further development and transformation stated.'

Since nations began there have been records of a statistical character. The rise of modern nations, with the growing sense of national unity and of international jealousy, gave rise to comprehensive descriptions of

'For general guidance the following works have been used: Von John, Geschichte der Statistik, erster Teil, von dem Ursprung der Statistik bis auf Quelclet (1835), (Stuttgart, 1884); August Meitzen's HistoryTheory and Technique of Statistics, tr. by Roland P. Falkner, Supple, ment to Annals of the American Academy of Political and Social Science, March, 1891. 
nations and estimates of their relative resources in men and materials of war. Meitzen' finds the first of these in the Cosmographia (1536 and 1544) of Sebastian Muenster. This work treated systematically Europe, Asia and Africa, covering the geography, history, manners and customs, industries, commerce, political and ecclesiastical organization, and military power of all known countries. This was followed by others of the same nature, which furnished the basis for the development of statistics as a discipline in the German universities. The first university lectures of such character were those of Herman Conring ${ }^{3}(1606-1681)$. These lectures were begun at the University of Helmstädt in 1660 and were published first in 1668, but in best form, posthumously in 1730. Volume four of the latter edition treats of "Slalskunde" or " notitia rerum publicarum."

According to Conring the notitia rerum publicarum treat of the condition of individual states in whole or in part, and properly should be confined in time to the present. The chief aim is to gain a knowledge of the state for the guidance of practical statesmen. For this reason they treat not only facts, but causes. Conring, being scholastic in his treatment, gives as causes the Aristotelian classification. The material causes are land and people; the formal and final are the kinds of union. such as government and administration, with reference to special objects of state; and the efficient causes are the revenues and land and sea power. Conring's work is

'Op. cit.. p. 20.

'See especially Von John. op. cil., p. 34. et see.

-Meitzen, p. 21: John. p. 52: Block. Traitt theoretique et pratique de slatistigue (2nd ed.. Paris, 1886). pp. 4-5.

-This work was entitled Exercilatio historico-politica de notifia singaJaris alicujus reipublicae. 
worthy of much emphasis. It was the first notable attempt at the systematic presentation of both the theory and the material of political statistics. The form he gave to such presentation was lasting. John observes that "a comparison of the theories set forth a century later by Achenwall, Von Schlözer and followers always discloses again this scholastic system formulated by Conring." For this reason "the great German poly-histor of the seventeenth century can alone be called the 'father' of this " form of statistics." 3

Meitzen, however, falls in with the custom by designating Achenwall (1719-1772) "the father of statistical science." Achenwall tells us " that his first statistical work was his Vorbereitung zur Statswissenschaft der europäischen Reiche, published in 1748 . This appeared as the introduction of a work of the year following, entitled Abriss der Statswissenschaft der europäischen Reiche. ${ }^{6}$

The advance of Achenwall over his predecessors was in more systematic treatment and more exact definition. This is evidenced by the manner in which he takes up the theoretical problems. "Before we begin to observe the constitution of the most important European states of to-day, it will be fitting to make some general remarks

'Op. cit., p. 6r.

"The word "this" evidently"refers to the German university statistics.

Ibid., p. 70.

'Op. cit., p. 22. See Block, op. cit., p. 7.

'Statsverfassung der heutigen zornchmsten curopäischen Reiche und Völker im Grundriss, edited by M. C. Sprengel (Göttingen, Ist pt.. 1790, 2nd pt., 1798), Vorrede zur erslen Ausgabe.

'This ran through five editions in the author's lifetime; a sixth was brought out by Von Schlözer in 1781. References here are to the seventh edition by Sprengel. the Stalsverfassung mentioned in the preceding note. 
on 'Statistik," as that discipline which is concerned with this object; to set forth its meaning. limit and divisions and its natural connections; as also to indicate briefly the uses, the history and the sources of the same." - In observing a state, Achenwall says that he finds many things which notably advance or hinder its prosperity. "Such things can be called Statsmerkwürdigkeiten", (the noteworthy things of a state). "The totality of the actual 'Statsmerkwürdigkeiten ' of a kingdom or republic makes up its constitution in the broadest sense; and the account of the constitutions of one or more states, treated individually, is 'Statistik, (Statskunde), oder Statsbeschreibung.'.' 'Statistik' studies the life of a state with a view of ascertaining its sources of weakness and strength.s It will not include all facts of interest regarding a state, but only such as are important for "politische Kenntniss," " that is, 'Statistik' seeks to obtain, through a description of the state, a guide for the statesman.' Though thus limited, 'Statistik' still included much that later became differentiated, as geography, ethnography, public and administrative law and political economy. Achenwall's work was translated into many languages and his definition of statistics thus came into general use.

'Statistik' thus owed the fixity of its definition to Achenwall, but there was little change in the real character of the discipline from the very early time of Muenster to the beginning of the last century. Von Schlözer epitomized the definition," and he and other representa-

"He first uses this word in the "Vorrede" of the first edition.

- Vorbercilung. p. 2.

Ibid.. p. 4 .

'Ibid., p. 5 .

Jbid., p. 6. - lbid.. p. 6. 'sbid.. p. 46.

-." Statskwnde ist cine stillstehende Statsgeschichte: so arie diese cime fortlanfende Stalskunde." ibid.. p. 5, in brackets. 
tives of the school made such improvement in the analysis and arrangement of results as the continued enrichment of material suggested. Both the theory and the method were simple. This school of statisticians believed the possibilitics of their science were exhausted by $\checkmark$ a verbal description of a contemporary social condition, so arranged as to be useful to statesmen, and accompanied by general observations on the results. But an almost revolutionary change was impending. A symplom of this change is found in the works of Ancherson: (174I) and Büsching'(1758). Though Achenwall had stated that knowledge of the strength of a nation would require a comparison of its resources with those of other nations, ${ }^{3}$ these men were the first to make such comparisons directly. Moreover, they used, so far as possible, numerical tables drawn from official sources. Besides, Büsching gave slight space to the geography, constitution and administration of the countries described and emphasized the economic and material factors of social life.

But the real change followed the establishment of statistical bureaus and the publication by them of the results of censuses and inquiries. "Die Tabellen-Statistik" quickly came into vogue. A tragic, but bloodless, warfare ensued between the orthodox statisticians and the worshipers of rows of figures. ${ }^{4}$ The latter had the assistance of continuous new recruits in the form of large quotas of official numerical data, which could not fail of

'Von John, op. cit., p. 88.

'Meitzen, op. cil., p. 24, el seq., and p. 41.

- Vorbereitung, pp. 47-48.

-The followers of Achenwall claimed that their statistics were " the right eye of political science," and accused the table statisticians of reducing statistics to a "veritable cadaver, on which one could not look without abhorrence," Von John, of. cit., p. 129. 
effect. When the atmosphere eleared it was found that a considerable change had been wrought in the character of descriptive statistics. 'Statistik' disappeared as a university discipline and was replaced by two rather distinet kinds of descriptive material in which numerical tables and verbal explanation divided honors. These two were the official statistical publications, and the statistical compendiums prepared mostly by private enterprise.

Much of Quetelet's activity was connected with perfecting these two kinds of statistical works. His own definition of statistics ' evidently restated that given by Achenwall and Von Schlözer, and the objects of statistical inquiry, as given by him ' were those treated by this school. But we shall see that it was primarily his own activity that led to the conception of statistics as a method of observation based on enumeration and applicable to any field of scientific inquiry. It is impossible to state just what elements in the betterment of descriptive statistics were due uniquely to Quetelet, but he contributed to the development in the following ways: (1) perfection of plans for census taking: (2) criticism of sources; (3) arrangement of materials; and (4) progress toward uniformity and comparability of data.

Quetelet's direct interest in public statistics dates from his appointment in 1826 as correspondent for Brabant to

'Letters on the Theory of Prababilities, as Applied to the Monal and Political Sciences, translated from the Firench by $O$. $G$. Downes (London, 1849), pp. 176, 179, 180, 182.

'Ibid.. p. 183. Note also headings treated in "' Recherches statistiques sur le royaume des Pays-Bas." Nowreanx memoires de racedbuie royale des sciences ef belles-letlres de Bruxelles, vol. v (1829), and the elaborate Slatistique internotionale. Bulletin de la connmission centrake de statistique (Bruxelles), vol. $\times$ (1866). 
the statistical bureau of Holland. His connection with the carly censuses of Holland (1829) and of Belgium $\left(183^{2}\right)$, his position as supervisor of the statisties of the administration and later as president of the Commission centrale, made it possible for him to impress a high character of excellence on the statistical publications of his own country. He gave careful consideration to the collection of data. both as to the blank forms to be used and as to the nature of the questions to be asked, to the tabulation and forms of presentation of the material, to methods of averaging and summarizing data, and to the criticism, both of the sources and of the results of the investigation.

The practical rules developed by him still form the essential guides in census taking.' His predecessors had given some attention to the criticism of results, but Quetelet assisted materially in the advance of criticism of sources. ("Statistics are of value only according to their exactness. Without this essential quality they become useless, and even dangerous, since they conduce to error." " He insisted that every statistical work should give both the sources of the data and the manner of their collection. The checking of statistical documents, he held, should be both moral and material. ${ }^{3}$ By moral examination he meant an inquiry into the influences under which the data are collected and the nature of their sources. The material examination consists in observing whether the numbers are sufficiently large to assure the predominance of constant causes, and suficiently continuous or uniform to make certain that accidental causes have not unduly infuenced some of them,

'See Lelicrs, p. 195, el sca.

'Ibid.. p. 108.

"Ibid., "Letter xxxix." 
and whether they have been combined with mathematical accuracy. As to the arrangement and presentation of results, Quetelet made progress both in official documents, so as to secure clearness and ready comprehensibility, and in scientific studies, so as to show the greatest possible number of correlations. To group the data so that permanent factors would be thrust into prominent view, and so as to make comparisons on the basis of time, place, sex, age, elc., easily possible, were essential principles with him. I The study of correlations, the attempt to find the causal relations of phenomena, marks a very great advance over the works in this particular line of statistical development. | Such studies required the development of a more precise technique, which, in turn, reacted on the criticism of sources and gave to descriptive statistics a deeper significance. It is precisely at this point that descriptive statistics felt most decisively the influence of the statistics begun by the School of Political Arithmetic. And it is in and through the work of Quetelet that this influence was first clearly exerted. That is, the development of official statistics furnished more abundant numerical data, and the elaboration by Quetelet of a method for treating such data made possible fthe correlation of statistical results with economic and social conditions and the consideration of questions involving the public weal. The disciples of Achenwall had upbraided the table statisticians with neglecting the consideration of the deeper questions of social life. They failed to recognize the necessity of precise data, of number and measure, in order to draw reasonably correct and at the same time significant conclusions on such questions.

Finally Quetelet contributed to the progress toward uniformity and comparability in official statistics. By 
comparability he meant two things, namely. (I) uniformity of all data collected under a given schedule for one time and place, and (2) uniformity of all data under a given schedule for different times and places.' Uniformity of the first sort is absolutely essential to the validity of any conclusions whatever. Uniformity for different times makes possible the measurement of the change in a social condition within a nation through a period of time, while uniformity for different countries makes possible the direct comparison of social conditions in these countries. Quetelet would not only test the progress of his own country but he dreamed of presenting in comparable data the status and the progress of all nations. Hence his leadership in the organization of the International Statistical Congress. In his opening address, as well as in the formulation of the plans for the first session, Quetelet sounded the keynote of this movement in his emphasis on international uniformity. He felt keenly the need of comparability among the official statistics of western nations. This end was to be realized through the collection of material on the basis of a common plan, following similar instructions, classifications and schemes of presentation and using the same terminology. This end is still far from realization, but there can be little doubt that through this Congress Quetelet influenced, directly or indirectly, the statistics of many nations. The value to science of the realization of international uniformity would be immense, inasmuch as it would make possible a multitude of correlations and comparisons that are now either dangerous or altogether impossible.

Another line of statistical development gave rise to 


\section{7]}

very different conceptions and methods. In 1662 Captain John Graunt, F. R. S. (1620-1674) presented to the Royal Society his Natural and Political Observations upon the Bills of Morlality with reference to the Government, Religion, Trade, Growth, Air, Diseases, and the several changes of the City of London.' This work has not been sufficiently emphasized by the historians of statistics. As a scientific study of population it was not surpassed until the appearance of Süssmilch's work, eighty years later. It contains the first presentation of a number of the inductions from population statistics, which Quetelet presented much more convincingly and impressively in Sur l'homme, published in 1835 . Graunt found that the deaths due to various diseases and even to certain kinds of accidents " bear a constant proportion unto the whole number of burials." He pointed out the constancy in the number of abortions and still-births: ${ }^{3}$ the variation of the death rate by seasons: ' the ratio of births to deaths in city and in country $;^{3}$ and the ratio of male to female births ${ }^{6}{ }^{6}$ he also presented the rough outline of a table of mortality.'

The interesting feature of Graunt's work is not the approximate accuracy of his conclusions, but the method he followed. He was permeated with the Baconian philosophy and sought truth through observation rather than speculation. His conclusions were faulty both because of the incompleteness of his data and his utter lack of comprehension of the law of large numbers. His mortality table is, in fact, only a piece of rational guesswork. But his book stimulated the widest interest, and.

'References here are to the sth edition. London, 1676.
- rbid.. p. 26.
'sbid., p. 4 s.
'Jbid., p. 56.
- Jbid., D. 57. of seg.
1bid., pp. 87. 103-104.
'Moid.. pp. 83-84. 
above all, opened the way for a new method of studying social life, namely, observation, enumeration and calculation. It is with Graunt, in fact, that we find the beginning of statistics as a method of observation in the service of inductive social science. '

Petty's first researches were stimulated by Graunt's Observations, which he designated as "a new light to the world." " Petty was dominated by the same empircal philosophy; he would " use only arguments of sense," and would express himself in terms of " number, weight and measure." ${ }_{3}$ Owing to the dearth of accurate enumerations he resorted to calculation, as, for example, the estimation of the number of inhabitants from the number of houses, or from the number of deaths. He appreciates the value of an average of several such computations, and "pitched the medium" " between extreme estimates.

The cultivation of Political Arithmetic, "the art of reasoning by figures upon things relating to government," ${ }_{5}$ was continued, notably, by Davenant, Arbuthnot and King. The essays of these writers were used by Sir Wm. Derham, F. R. S., in his Physico-Theology; or a Demonstration of the Being and Attributes of God from. his Works of Creation. ${ }^{6}$ This work is an elaborate argu-

\footnotetext{
'For an excellent estimate of Graunt's influence see The Economic Writings of Sir Wm. Pelty (Cambridge, 1899 ), by Chas. H. Hull, vol. i, pp. Ixxv-lxxix. He traces this influence through Derham, Süssmilch and Malthus to Darwin.

'Observations upon the Dublin Bills of Mortality (1681), to be found in Several Essays in Political Arithmetick (London, 1699), p. 55.

"Ibid., "Preface."

'Ibid., p. 123.

- Davenant, Discourses on the Public Recienues, and on the Trade of England (Londion, 1698), pt. I, “'Discourse I,” p. 2.

'Londion, 1699.
} 
ment from design. He finds in the admirable proportions of marriages to births, of births to deaths, of males to females, the surest evillence of "the work of One that ruleth the World." The perusal of Derham's Physico. Theology by Suissmilch, led him to undertake researches on the number of births, deaths and marriages according to the lists of the city of Breslau." Meanwhile, he sent to England for the writings of Graunt and Petty.' His writings, especially the second edition, proved to be a great advance upon the preceding, not only in the variety and exactness of conclusions, but also in the clearer connection between the concrete phenomena of social life and economic conditions.

Moreover, he made distinct advances in method. Upon those wishing to controvert his conclusions he imposes the following conditions:

(1) The lists must be correct, else contradiction is of no value. To this end it is necessary to consider well the conditions and changes of a place, to see whether war, plague or other disease has wrought any variation. (2) The numbers must not be small; the greater they are and the more years included thereunder the better. ... If I have a hundred cases in support of my conclusion, then can nothing to the contrary be drawn from one case."

It was, in fact, only by observing large numbers that he

'Eighth edition (London, 1727), bk. iv. chap. 10, "' Of the Balance of Animals or the Due Proportion in which the World is stocked with them."

'Die götlliche Ordnung in den Veränderungen des menschlichen Geschlechls (Berlin, ist ed., 1742), "Vorrede," p. 13.

'Ibid., p. 16.

' 2 vols., Berlin, 1761 and 1762 .

"First edition, " Vorrede," pp. 38-39. 
could ascertain the great regularities in mathematical ratios which represented to him "the rules of order which God's wisdom and goodness have established."'

These quotations show Süssmilch's recognition in a general way, of three principles highly important for the development of statistical method, namely, (1) Social phenomena have causes; (2) the regularities found in statistical results reveal the rules of the existing social order; and (3) constancy in results can be obtained only by viewing large numbers." All of these principles are found in the work of Quetelet. It required only a change from a theological to a scientific viewpoint to expand the first of these principles into a complete denial of chance and the assertation of an absolute solidarity in the sequence and the co-existence of social phenomena. Such a view became a philosophical tenet, and was a favorite doctrine of Quetelet's great friend and teacher, Laplace. It appears in Quetelet's writings in the form, "effects have causes and are proportioned to them," a form which suggests the theory of probabilities. The second of the above principles remained without emphasis until Quetelet sought to find in the statistical regularities the laws of a social mechanics. The third was definitely recognized in the construction of mortality tables by Halley, Deparcieux, Wargentin and Kersseboom, and was well established as the "law of large numbers" by the development of the mathematical theory of probabilities.

Coming down to the early years of Quetelet's life we find the most significant influences on the course of development of the statistics of population and of statistical

'Second edition, vol. i, title page.

:On this see ibid., vol. ii, pp. 262 and 408. 
method in the works of Malthus, Laplace and Fourier. all of whom Queteict knew personally. Malthus's Essay on Population, though apparently not infuenced by Süssmilch's Gölliche Ordusug. gave a world-wide stimulus to the study of population in its economic and social aspects. Laplace continued the development of the theory of probabilitics and instructed Quetelet therein. Fourier's infuence was exerted through the Recherches statistigues sur la ville de Paris at le department de la Seine.' The first four volumes of this serics have introductory essays by Fourier of very great value. In the first of these, Notions generales sur la population." he develops both algebraic and geometrical expressions for tables of population and of mortality, average duration of life and expectation of life, assuming the population to be stationary. He points out the greater accuracy of results when age groups of one-half year or one month, instead of one year, are taken. Several principles of probabilities are stated and applied to the study of population. He inquires into the causes affecting the growth of population and classes these as general and fortuitous. He shows clearly the advantages of large numbers, and especially of averages deduced from a series of such numbers extending over several years. Finally he states repeatedly that average values depend on general causes, and change only very slowly "by the secular progress of institutions and customs."

In the memoir of the second volume of the Recherches statistiques should be noted the fourth section, Remarque générale sur le degré de précision des résuliats moyens.

'Paris, 6 vols.; Fourier's essays are in the volumes for 1821 (and ed.. 1833 ), 1823 (and ed., 1834), 18:5 and 1829 .

'Vol. i (1821), pp. ix-lxxiii. 
The third introductory essay, Mémoire sur les résultats moyens d'un grand nombre d' observations,' presents formulas for finding the degree of precision " and the probable error of the average. ${ }^{3}$ He presents a method of finding the quantity which when multiplied by three gives the positive and negative limits of error in a group of measurements, ${ }^{4}$ and when multiplied by .47708 gives the probable error, which he calls the average error. These results are then generalized in the Second memoire sur les résultats moyens et sur les erreurs des mesures, treating by the use of the calculus the probable error of a result derived from any number of values each having its own probable error. Quetelet undoubtedly had early access to these volumes and was much stimulated by them. ${ }^{6}$

Thus the School of Political Arithmetic in contradistinction from the descriptive school, began by laying emphasis on the method of inquiry. Their central object of statistical investigation was the population, and, as more abundant data accumulated, they perfected both their conclusions and their technique. This is especially true of the development of mortality tables, which by the close of the eighteenth century had led to consider-

'/bid., vol. iii (1826), pp. ix-xxxi.

'Ibid., pp. xv, et seq. and p. xxv.

'Ibid., pp. xviii, et seg.

- The probability is 199909 that the true result lies within A (average) $+3 \mathrm{~g}$ and $\mathrm{A}-3 \mathrm{~g}$.

'Ibid., vol. iv (1829), pp. ix-xlviii.

- Thus Quetelet says in the preface to Instructions populaires sur le calcul des probabilites (Brussels, 1828), that he has made large borrowings from Laplace and that "lessons 12 and 13 are extracted in great part from the excellent introduction to Recherches statistiques sur la ville de Paris." He should have included also lesson 14 , for it is clearly from the same source. 
able insight into the nature of statistical data and the true method of treating them. Finally in the works of Laplace and Fourier we note decided indications of a tendency to give direct attention to the problem of technique and to extend the application of such technique to observations of natural and social phenomena. It was the function of Quetelet to gather up these various tendencies, to perfect the method, to extend the scope of its application and to give the whole a new and profound significance. His activity may be treated under the headings, (I) population statistics, (II) moral statistics, (III) development of technique and (IV) application of the normal law of error to the physical measurements of men.

(I) The studies in the statistics of population comprised in Quetelet's works' may be classed under three

'The chief studies of population statistics are:

1. " Mémoire sur les lois des naissances et de la mortalité à Bruxelles," presented to the Brussels Academy, April 25, 1825. Nonveanx mkmoires de l'acad. roy. des sci. el bell.-bet. de Bruxelles, vol. iii (1826), pp. 493512.

2. "Recherches sur la population, les naissances, les déces, les prisons, les dépóts de mendicite, etc., dans les Pays-Bas," presented to the Academy. February, 1827, ibid., vol. iv (1827), pp. 115-165.

3. " Recherches statistiques sur le royaume des Pays-Bas," presented to the Academy. December, 1829, ibid., vol. $v$ (1829), pp. vi, 57 and tables.

4. Recherches sur le reporaduction et la mortalitt ef sur la poputation de la Belgigne. Publié avee M. Smits. Premier recueil officiel (Brussels, 1832).

5. Sur t'honome et te dficloppement de ses faculles, ow essaj de phy. sigue sociale (2 vols., Paris, 1835), book 1.

6. " De l'influence des saisons sur la mortalité aux différens àges dans In Belgique," Nowv. m\&m., vol. xi (1838), 30 pp.

7. "Sur le recensement de la population de Bruxelles." Bulletin de la commission contrale de statistique, vol. i (1843). pp. 27-164.

8. "Nourelles tables de mortalité pour la Belgique," ibid., vol. iv (185x), Dp. 1-22. 
headings, (a) studies of births, deaths and marriages, (b) treatment of the law of population, and (c) development of tables of mortality and of population.

The study of births, deaths and marriages had been treated in a most thorough-going and extensive manner by Süssmilch in his second edition of the Götliche Ordnung ( 1761 and 1762 ), but, since his time, there had accumulated a large quantity of material and there had been numerous more or less intensive researches on these subjects.' Among the most important of these were those by Quctelet's Parisian friends De Chateuneuf? Villermé and Fourier. The chief merit of Quetelet is in the comprehensiveness of his treatment of variots phases of births and dcaths. The best results of his memoirs preceding $I_{35}$, together with material gathered from many sources are found in the Sur l' homme. ${ }^{3}$

(a) Thus in the study of births he inquires into the effect of numerous natural and perturbative causes on both sex and fectindity; he inquires into the ratio of male to female births ( 1 ) throughout Europe, (2) in free and slave populations, (3) in town and country, (4) among legitimate and illegitimate births; he investigates the influence of age of parents and of conjugal condition

9. " Nouvelles tables de population pour la Belgique," ibid., pp. 71-92.

10. " Sur les tables de mortalité et de population," ibid., vol. v (1853), pp. 1-24.

11. "Statistique internationale (population) par A. Quetelet et X. Heuschling," ibid., vol. x (1866), CXV pp. of text and 406 pp. of tables.

Of these, numbers 3 and 10 might be classed as descriptive of official statistics.

'For list see references, Sur l'homme, bk. I.

"Von John, op. cit.. p. 333 note, says that De Chateuncuf, at the instigation of his friend Poisson, devoted himself most zealously to statistics.

'Sur l'homme, bk. 1 , chaps. i, ii and iii. 
on the sex of offspring; he studies the influence of age of parents, of place, of years of abundance and scarcity. of years of peace and war, of seasons and of hours of the day, on the number of births. All the foregoing being classed as natural causes, he studies profession, economic condition, morality and political and religious institutions as perturbative causes. Similar correlations were made for still-births' and for deaths.' These studies contain few conclusions that were new at the time, but because of their clearness and comprehensiveness in both material and number of correlations, they afforded a striking and stimulating indication of the advancement of vital statistics and were an excellent medium for the spread of such knowledge.

(b) Quetelet's treatment of the law of population' does not deserve lengthy treatment. The distinguishing feature about it is the statement that the resistance to the growth of population increases, all other things being equal, as the square of the rate at which population tends to increase. He presents neither data nor course of reasoning to support this conclusion nor does he explain any of the possibilities lurking in the phrase "all other things being equal." The theorem therefore is certainly not demonstrated.

(c) Quetelet's first statistical memoir, giving a table of mortality with a distinction of sex, sought to provide a reliable basis for life insurance in Brussels. A second memoirs extended the tables of mortality and of popula-

'Nowv. mem., vol. iv (1827); Sur l'homme, bk. 1, chap. iv.

Ibid.. bk. 1, chap. iv.

'Jbid., bk. 2, chap. vii.

-Nowv. mem., vol. iii (1826), pp. 493-512.

-Nowr. minn., vol. ir (1827). 
tion to the southern provinces, while studies of $1832^{\text {" }}$ and $1833^{\circ}$ gave tables for all Belgium. Quetelet early made the distinction of sex and fof residence in city or country; he also brought out the varying rates of mortality at different ages, as in the early months of childhood, at the ages preceding puberty, and at the ages twenty-four and thirty, in men. He perfected these tables on the basis of the registers of death for the five years $1841-5 .^{3}$ The chief importance of these tables lies in their great practical value in his own country. His first serious attempt at the treatment of the mathematical theory of tables of mortality and of population was in the memoirs of $185 \mathrm{I}$ and $1853 .^{4}$ This last memoir is in three sections, the first two of which treat these tables for a stationary population following very closely Fourier's method. He however makes the evident error of confusing the population at the end of a calendar year with that at the end of a year of life. The third section treats the subject for any population whatever. He however assumes that the births of a calendar year occur simultaneously and that all the generations represented in a population at a given time have the same rate of mortality whether the population be increasing or decreasing. Neither of these assumptions being true he fails to reach a general formula. Nevertheless his studies were not without value to the general progress of the theory. ${ }^{5}$

\footnotetext{
' k'echerches sur la reproduction el la morlalite de l'homme aux differens ages (Brussels, 1832).

'Sur l'influence des saisons et des ages sur la mortalite, presented to the Academy of Moral and Political Sciences of the Institute of France in 1833, reproduced in Sur l'homme, bk. 1 , chap. 5 , sec. 5 , and elaborated in Nouv. mem., vol. xi (1838).

"Bull. de la cent. com. de sta., vol. iv (1851), pp. 1-22.

' loid., pp. $71-92$, and vol. v (1853), pp. 1-24.

'See Knapp, Theoric des Berolkerungs-zecchsels, pt. 2, p. 93, et seq.; Block, Traite de statistique, p. 206, at seq.
} 
(II) In 1826 appeared the first of the Comples $g$ entraux det administration de la justice criminelle en France. In these annual reports were enumerated the number and kind of crimes and misdemeanors, as well as the sex, age, occupation and education of the accused. Quetelet uses these reports in his "Recherches statistiques sur le royaume des Pays-Bas." ' In this he compares the sexes as to the kind of crimes, presents the relative number of crimes committed against persons and against property at each age, and tentatively sets forth the relative degree of tendency to crime at each age." Comparing the figures for the three years, $1825-1827$, he emphasizes the "astounding exactitude with which crimes are reproduced." , He adds,

Thus we pass from one year to another with the sad perspective of seeing the same crimes reproduced in the same order and calling down the same punishments in the same proportions. Sad condition of humanity! The part of prisons, of irons and of the scaffold seems fixed for it as much as the revenue of the state. We might enumerate in advance how many individuals will stain their hands in the blood of their fellows, how many will be forgers, how many will be poisoners, almost as we can enumerate in advance the births and deaths that should occur.

The same year, 1829, A. M. Guerry brought out his Stalistigue compart de l' blat de l' instruction et du

'Nowv. mfon.. vol. v (1829). pp. 25-38; read to the Brussels Academy December 6, 1828.

'Ibid.. p. 33.

'Ibid., p. 35.

'Nowv. mem., vol. v. pp. 35 and 36. This quotation shows that Quetelet had reached, in 1828. practically the same position as in the "Recherches sur le penchant au crime aux differens àges" of 1831, which is usually treated as his first work in moral statistics. There is thus good ground for giving to Quetelet priority in this field, instead of to Guerty as is usually done. 
nombre ies crimes' in which was sought an cstimate of the moral level of France by the use of statistical data. So also, he and D'Ivernois endeavored to compare the moral level of different countries by comparing their criminal records. Quctelet had made such a comparison between France and the Low Countries in his "Recherches" of 1829," but Guerry and D'Ivernois saw no especial significance in the constancy of the numbers from year to year, while it was precisely this that Quetelet empliasized. ${ }^{3}$ This constancy of the budget of crimes was strikingly brought out in his "Sur le penchant au crime aux différens àges." " Regularity in the number of suicides was noted in the Sur l'homme, and the constancy in the number of marriages for each age and sex, first shown in this same work, became the principal object of his later studies in moral statistics.

Thus it was that, though Gucrry coined the term “moral statistics," Quetelet gave it significance. He did this in the following ways:

(a) He emphasized the relation of the statistical regularities to man's moral freedom. The regularities which Arbuthnot, 5 Derham and Süssmilch had found to be the surest evidence of a divine order maintained for the good of man, Quetclet elevated to the

'Paris, 1829.

'Nouv. meim., vol. v, p. 27, et scq.

${ }^{3}$ Jealousy seems to have existed between Quetelet and Guerry. The former, however, relented and in 1847 used Guerry's term "statistique morale," but the latter remained uniriendly to the last. See especially "Note" following "Recherches sur le penchant au crime" and note in Sur l'komme, English translation, p. 96 , near the end of book third.

'Nouv. mém., vol. vii (1831), 81 pp.

3. An argument for Divine Providence, taken from the constant Regularity observed in the Births of both sexes," Phil. Tr., vol. xxvii. 
rank of social laws, comparable to the laws of physics. He gave a scientific, rather than a theological interpretation of the facts and thus threw loubt on man's free will. "It seems to ine that what relates to the human species, considered en masse, is of the order of physical facts." The possibility of predicting in advance the number and kind of crimes weighed heavily, at times, upon Quetelet's humanitarian spirit. "This possibility . . . must give rise to serious reflections, since it concerns the late of several thousand men who are diriven, as it were, in an irresistible manner toward the tribunals and toward the condemnations that await them." " The picturesqueness of his language and the clearness with which he joined the issue, compelled attention and led to wide discussion of the true nature of /statistical regularities and their ethical implications.

(b) At the same time that Quetelet held his averages to be " of the order of physical lacts," he held them to be dependent on social conditions and therefore to vary with time and place. This made possible the study of causal relations in social phenomena, for a change in social conditions would be followed by a change in the averages. Thus, social conditions were made responsible for the criminal budget and moral statistics was directly connected with social science. The problem then became that of expressly connecting social evils with certain social conditions, and by changing the latter also change the former.

(c) But this study of casual relations requires much more critical methods of treatment than a purely descriptive problem. The basic principles of the method presented by Quetelet for this study were derived from the

'Nowv. mkm., vol. vii, p. So.

: Boid., p. 23. 
theory of probabilities. They were: $(a)$ effects have causes and are proportioned to them, and $(\beta)$ reliable conclusions can be deduced from large numbers only. These principles are strikingly like those recognized by Süssmilch,' but no doubt they reached Quetelet by way of French mathematicians and astronomers, rather than directly or indirectly from the German theologian and statistician. From the first of these he derived the principle that man's moral and intellectual nature would be shown in his actions, and that the true nature of a social state would be shown in its products. But the effects of fortuitous circumstances can be avoided, and the resuits of general conditions can be seized, only by considering large groups of homogeneous data.

(III) These principles formed a part of his general development of the methods of statistical inquiry. The essential features of this are to be noted later, "hence it will suffice here to say that, although most of the principles utilized by Quetelet in the development of the normal law of error and its use in statistical inquiry had been already developed by the students of probabilities and in the essays of Fourier, yet it was doubtless the writings of Quetelet that led to their general appreciation and adoption. This was due to the clearness with which he stated the results of mathematical analysis and to the wide public which his writings reached. It may be emphasized here, moreover, that it was largely through GQuetelet's application of the same statistical method to anthropology, meteorology, astronomy, medicine and social science that arose the conception of statistics as a widely applicable method of observation.

(IV) But there is one feature of the application of this

'Sce pp. 47-48, supra.

${ }^{2}$ Chapters iv and $\mathrm{v}$. 
normal law of error which is distinctly his own, and which has been of especial significance both for the further perfection of statistical method and for the de. velopment of biological science. He likened society to a body having as its center of gravity the average man.' The determination of the properties of this average man would, he thought, give a true picture of the general features of the social body. These ideas were first presented in "Recherches sur la loi de croissance aux différens ages," " in which was presented the average height of groups of individuals of each age from birth to maturity. It was not, however, until much later that the idea of the average man as a type about which all men of the same class were grouped in accordance with a definite law was expressly developed.' The average man as a type varies with time and place. Similar concepts were readily applicable to any plant or animal. What was true of the distribution of the heights of men might prove to be true of any characteristic of a plant or animal; and what was true of the average man might prove to be true of the type of a species. Hence the possibility of studying the subject of biological variation by means of exact numerical measurements.

The preceding survey of Quetelet's statistical activity shows both its broadly inclusive character and its epochal importance in the history of the science. It is with good reason that Von John declares that "Quctelet's masterpiece of 1835 . . . is in fact a landmark in the historical

'See chap. iii, infra.

'Nowv. metro., vol. vii (1831). 31 pp.

'See chap. iii, infra.

- Quetelet was not consistent on this pcint of the variability of the average man. 
development, not only of political arithmetic, but also of the German university statistics." Among the causes of this eminent position must be included ( 1 ) the abundance of new data; (2) Quetelet's close contact with the French scholars interested in the theory of probabilities and in statistics; and (3) the wide publication of his results.

The abundance of new data was of primary importance. It made possible the comprehensive treatment of vital statistics, including a practical table of mortality for Belgium, and it raised questions of criticism of sources and of method of treatment. Official documents being a chief source, Quetelet exerted upon them a farreaching influence both through his own writings and the movement for international comparability represented by the Statistical Congresses. He was, in this way, largely instrumental in bringing such documents to a character mid-way between the purely verbal Achenwall-statistics and the purely numerical table statistics, by including with the tabular results descriptive and explanatory material. He extended the scope of statistical inquiry by adding the new field of moral statistics. It was mainly by this addition and the results following thereupon that the term first used to designate a new discipline in the German universities came to have that scientific character sought by the school of political arithmetic. Emphasizing the connection between social conditions and statistical results, he made the fundamental aim of the science of statistics the study of the co-existence and sequence of social phenomena in correlation with the environing conditions of social iife.

But he not only gave meaning to statistics as a descrip-

'Geschichie, p. 3;0.

'Sur l' homme, bk. i. 


\section{3]}

tive science, he also developed the conception of statistics as a method of scientific investigation serving all the sciences of observation. The law of error, developed by astronomers, and the theory of probability, cultivated zealously by that group of bright men eentering around the great Laplace, found in the writings of Quetelet both simplification and claboration and a channel of communication to an extensive group of reaclers. Moreover, this method found a new, and, to-day, highly significant extension in his studies of physical anthropology.

Finally should be emphasized the lact that practically everything of importance that Quetelet hit upon, he published time and again. The Correspondance mathematigue ef physique, the Nouveaux memoires, the Bulletins. and the Annuaire of the Brussels Academy, the Annuaire of the Observatory, and the Bulletin de la commession centrale de statistique, as well as his numerous works, furnished a varied means of communication with an extensive public. If further means were needed they would be found in his voluminous correspondence and in his connection with learned societies throughout the world.

Quetelet thus gathered up the chief statistical tendencies of his time, and contributed, in more or less notable degree, to the advancement of each. His genius consisted not so much in original conceptions as in a keen appreciation of the importance of various ideas and the great practical sense with which he applied them. 


\section{CHAPTER III}

THE AVERAGE MAN

Quetelet's name is customarily associated with the term average man (homme moyen) and with considerations on the importance of this homme moyen for a statistical study of society. The ideas involved in the concept, average man, are central in all of Quetelet's researches and are critical for an understanding of his writings. Apart from the unity derived from the more or less general presence of the notion of the average man, his writings on population and moral statistics, physical anthropology, statistical methods and the social system are completely lacking in a unifying principle. G. F. Knapp holds that there was no continuous unfolding of Quetelet's chief ideas.'

No doubt the germ of all he has to say is found in the writings preceding the Sur l'homme of 1835 , but Quetelet himself has indicated the natural development of his central thoughts. He says in the preface of Du Systeme social that in his first work, Sur l' homme, he presented the idea of the average man as the mean between two limits; that in the Letters he showed that the average man as to height is a type about which the heights of other men are grouped according to the law of acci-

1" Bericht über die Schriften Quetelcts zur Socialstatistik und Anthropologie." Hildebrand's Jahrbücher für Nationalökonomie und Statistik, vol. xvii, p. 358 . 
dental causes. "In this new work I show that the law of accidental causes is a general law which is applied to individuals as well as to peoples and which dominates our moral and intellectual qualities as well as our physical qualities." ' There was thus, after 1835 , development in the concept of the average man and an extension of its application as a means of interpreting social phenomena.

A brief survey of this development and extension will serve to bring out the nature of this concept in its final form. The first researches on the qualities of the average man dealt with the physical qualities of height and weight, which are susceptible of direct measurement. In the memoir "Recherches sur la loi de croissance de l'homme" "he says,

The man that I consider here is analogous to the center of gravity in bodies; he is the mean about which oscillate the social elements : he is, so to speak, a fictitious being for whom all things proceed conformably to the average results obtained for society. If we wish to establish the basis of a social mechanics (mecanigue sociale), it is he whom we should consider, without stopping to examine particular or anomalous cases.

Thus the normal law of growth expressed in tabular form for each sex gives the average heights of male and female Belgians, at each age, from five months preceding birth to maturity, at about the ages of twentyfive and twenty years, respectively. These tables do not show the heights any particular individuals will attain at given ages, any more than a mortality table would give the time of death of particular persons, but they give

'Dw Syst2me social at des lois qui le rtgissent (Paris, 1848), p. ix.

Nowr. mewr., vol. vii. 
rather the height of the average man at each age. The normal law of growth thus shown applics to the whole group of Belgians of either sex, viewed as an aggregate. It is the law of growth for the average man, the heights given being those about which the heights of all persons of given age and sex "oscillate." Just how this oscillation takes place Quctclct does not at this time state. He did state however that studies similar to this on the law of growth in height should be made for man's various physical, intellectual and moral qualities.

In the men:oir "lecherches sur le penchant au crime aux différens àges," " he uses the term average man (homme moycn) for the first time. " If the average man were determincd for a nation he would present the type of that nation; if he could be determined from the enscmble of men, he would present the type of the entire human species." He here studies the possibility and the means of determining the average man and hints at the average man as the type of the beautiful.

The next memoir ${ }^{2}$ studies the relation of height to weight at each age, but it adds nothing to the general notion of the average man. The Sur l'homme gives, besides a reproduction of the preceding studies, much general discussion of the average $\operatorname{man}^{3}$ but adds little to the precision of the concept. But in the article "Sur l'appréciation des documents statistiques et en particulier sur l'appréciation des moyennes" 4 is developed carefully the view of the average man as a $t y p c$. Here, for the

'Nouv. mem., vol. vii, p. I of the memoir.

'Recherches sur le pcids del'homme aux différens àges, N'ouv. mtm., vol. vii.

'Especially bk. iv.

- Bulletin de la com. cent. de stat., vol. ii (1845), pp. 205-287. 
first time, he gives exact connotation to the word type and shows just how the members of a group oscillate about the average. Even in the first memoir ' certain of the tables showed symmetrical distribution about the average, but Quetelet did not comment on the symmetry. But in this later article this distribution is his theme.

Haring established his scale of possibility, he begins an examination of the manner in which the numbers from which an average are deduced are grouped about it." He first distributes 8192 measurements of the height of the same person about the average, seven groups above and seven below, according to his scale. This leads to the question

whether there exists in a people a type-man, a man who represents this people as to heiglit and in relation to whom all the other men of the same nation might be considered as presenting variations more or less great. The numbers we would obtain in measuring these latter would be grouped about the average in the same manner as those which we would obtain if the same type-man were measured a great many times with means more or less clumsy.'

A study then of the distribution of the chest measurements of 5738 Scotch soldiers and of the heights of 100,000 French conscripts shows a close agreement between the actual distribution and that calculated according to his scale. In fact he believes that in the latter case he is able to prove fraud by the lack of continuity in the actual distribution: a congestion below the required height and a scarcity just above it indicate that some 2000 have escaped service by reducing their height

" Recherches sur la loi de croissance de l'homme."

". Sur l'appréciation, elc." p. 250.

'Boid., p. 258. 
two or three centimeters. Thus he finds not only confirmation but a practical use of the conception that there is a type-man from which all men are but variations.

In the Letters' the matter is further elucidated with much of the same data. If one should make 1000 measurements of the chest of the Gladiator, or of a living person, or if 1000 sculptors, working without preconceived notions, should copy the Gladiator and their copies should be measured, each set of measurements would be grouped in accordance with the law of possibility. If we assume that one would likely as not make an error of one incli in measuring the chest of a living person, then the chest measurements of the 5738 Scotch soldiers are grouped with as much regularity as would be the same number of measurements made on one individual. "The measurements occur as though the chests measured had been modelled from the same type. If such were not the case the measurements would not, in spite of their imperfections, group themselves with the astonishing symmetry which the law of possibility assigns them." To the objection that the Scotch soldiers represent a selected group, Quetelet replied that the accurate verification of the principle is more easy when all the men of a nation are taken; the only effect of embracing a larger number is to widen the limits of variation. ${ }^{3}$

In similar manner Quetelet then treats the heights of I00.000 French conscripts. The probable error in this case, however, is two inches, and his argument for the existence of a type rests on the condition that a very

'Letters on the Theory of Probabilities, trans. by Downes (London, 1849), pp. 90-105.

'Ibid., p. 93.

'Ibid., p. 94. 
unskillful person with crude instruments would be liable to an error of two inches in measuring a conscript of the average height.

Everything occurs then as though there existed a type of man from whom all other men differ more or less. .. . Every people presents its mean and the different variations from this mean in numbers which may be calculated a priori. This mean varies among different peoples and sometimes even within the limits of the same country, where two peoples of different origins may be mixed together.'

Thus was presented the definite concept of the average man as a biological type, about which the actual men of a given group were distributed according to the normal law of error, or the law of accidental causes as Quetelet called it. This type was always spoken of as due to constant causes and the variations from it as due to accidental causes. The next step was to generalize this concept by extending it to all of man's physical properties and to his intellectual and moral qualities, whether with reference to the normal state of an individual, or to the average man of a nation or of humanity considered at a definite period of time, or through all the vicissitudes of national and human history.

This generalization is the theme of the Systime social. This work is divided into three books devoted respectively to man, societies and humanity. The first two books are divided into three sections each, treating respectively the physical, moral and intellectual qualities, while the third considers in a general way the effect of progress in knowledge on these various qualities, their relations to each other and the limits through which they

'Lethers, p. 96. 
vary. Probably most of the points made in this work had been previously noted by Quetelet, but here they are grouped systematically. The aim is to show the universal validity of the law of accidental causes. "There is a general law which dominates our universe . . . ; it gives to everything that breathes an infinite variety." : "Among organized beings all elements vary about an average state, and these variations, due to accidental causes, occur with such harmony and precision that we can, in advance, classify them by number and extent.",

Thus the average man, at first somewhat vaguely conceived as a mean between limits more or less extended, was at length definitely conceived as a type. His delineation was based on a law derived from the mathematical theory of chances but believed to have the widest possible realization in the phenomena of organic nature. The average man, according to Quetelet, will show the effects of the operation of "constant" causes, while the variations about him will show the effects of "perturbative" or "accidental" causes. Thus we have here not only a manner of viewing living things, but a criterion for distinguishing that which is typical and general, from that which is only individual.

In the determination of the properties of the average man, Quetelet carried on many extensive researches. This was in fact the particular aim of most all of his statistical studies. From the data of population statistics he sought to discover the conditions attending the birth of the average man, and the time and conditions of his death. The law of growth showed the height of the average man at each age. ${ }^{3}$ This was followed by a mul-

\footnotetext{
' Du Systime social, p. 16.

=Ibid., p. 17.

". Recherches sur la loi de croissance de l'homme."
} 
titude of studies of men's physical proportions at each age culminating in the Anthropombtric of 1871 . Similar studies in the development of mental and moral traits were those dealing with the products of dramatic talent ' and with the propensity to crime." Still other moral qualities of the average man were sought in the study of foresight, of suicides' and of marriages.' All of these studies have great historical significance. Those in the physical proportions of men were the precursors of the physical measurements of criminals as a means of identification, and of the measurement of head forms and other bodily parts by physical anthropologists as a means of racial discrimination. Especially were they the antecedents of the studies in biological variation which bid fair to make of biology a relatively exact science. Quetelet's studies of mental trials were the forerunners of studies in experimental psychology, which seem destined to lay the foundation for a science of education. Finally the studies in moral statistics opened the way for the inductive study of social life.

Quetelet presented a most important and extensive role for the average man.s Many scientists, so Quetelet thought, would find his properties of the highest usefulness. The physician could thus determine the most useful remedies and the action to be taken, both in the usual case and in the unusual, by comparing his patient with the fictitious average. The artist and man of letters

'Sur l'homme, bk. iii, chap. i.

'Especially " Recherches sur le penchant au crime aux différens àges." Nour. minn., vol. vii.

- Sur l'komme, bk. iii, chap. ii.

-Especially "Statistique morale," Bulletin de la conn. cent. de stal., vol. iii, and "Sur la statistique morale," Nowr. m\&n., vol. xxi.

'Sur l' hoomome, bk. iv. 
could thus present a most truly representative art and literature. The politician could thus more accurately play upon the general sentiments and beliefs in the formation of public opinion. The naturalist by the use of the average man could fix racial characteristics and demarcations, and determine the extent of any changes in racial types from time to time. Finally the social scientist, by determining the average man for various nations, from year to year, throughout the course of national history, would be able to ascertain for nations as well as individuals, their laws of birth, growth and decay, of equilibrium and motion,-the course followed, so to speak, by their centers of gravity.

There is something fascinating in this conception of the average man, while the task of its complete realization is stupendous. It is a statistical conception of the universe possessing qualities of poetic and artistic beauty. Everything is to be viewed as varying about a normal state in a manner to be accurately described by beautiful bell-shaped curves of perfect symmetry but of varying amplitude. Thus it is that the individual varies about his normal self; thus members of a group vary about their average; thus the men of a nation, viewed as individuals, vary about the average man of the nation; thus a nation varies about its normal state; and finally, inasmuch as the qualities of the average man change from time to time and place to place in obedience to general causes, to follow the course of the average man in the whole series of nations would give us, in Quetelet's view, the principles of a social physics, the true mechanics of human history.

One of the early objections made to the conception of the average man was that he could not be constructed as a composite being; that the attempt to put together 
numerous average qualities would result in a monstrosity. Cournot argued that the averages of the bodily proportions of a group of men would not be consistent with one another or with the conditions of viability.'

Such objections have often been repeated. But stech controversy comes to naught. Quetelet himself called the average man a "fictitious being" in his first use of the term." It would seem then pertinent to remark that the conditions of viability for a fictitious being, or the general harmony of his parts, can have only a speculative interest and value. The result obtained by dividing the sum of a series of measurements by their number is merely a numerical average and becomes the quality of an average man only by a flight of constructive imagination. The average height of a group is readily transposed into the heiglit of the average man of that group, but no practical utility is gained by such transposition. It may also be stated that the cssential thing is adequately to represent the group, and, for this purpose, the average alone is not sufficient. Significant changes may occur in

'Cournot reasoned by analogy. He stated that the averages of the sides of a series of right triangles do not give a right triangle; nor are the sides, angles and areas of a series of any kind of triangles so consistent with each other as to form a triangle. In like manner average bodily proportions will not fit together so as to make life possible. See Exposition de la theorie des chances et des frobabililts (Paris, 1843). pp. 213-214. Quetelet replied to this in Du Systeme sacial, p. 35. et seq. He divided a group of thirty men into three sections in such a way that the average heights of all three were the same. He then found that other average measurements for the three sections were nearly the same. He believed this experiment proved Cournot's criticism invalid. Now while Cournot's reasoning by analogy is not convincing. Quetelet's experiment does not meet the isste. It proves only that the averages of the same trait of several homogeneous groups are nearly equal, not that the averages of several different traits are mutually harmonious.

See p. 63. supra. 
the limits of distribution, or in the standard deviation of the group measurements, without affecting the average. Moreover, in problems of correlation very great importance attaches to the association of group characteristics throughout the whole scale of distribution.

It was one of Quetelet's repeated assertions that the average man was the type of perfection in beauty and goodness. Believing the race to be intellectually progressive, he held the average man to be the most perfect intellectually, only for the time being. But believing the race to be morally unprogressive, he held the average man to represent the type of the absolutely good. The systematic presentation of Quetelet's argument on this point should begin doubtless with the assumption of perfectly normal distribution of every characteristic. This he fairly well established in connection with physical measurements, and he assumed it with reference to mental and moral traits. With respect to physical man he then represented nature as an artist making a multitude of copies of the type-man, a type which, he thought, remained ever the same ${ }^{x}$ though actual men might vary from it more or less. The type was in his mind directly comparable to the true ratio of white and black balls in the urn from which chance draws are made, a ratio to be indefinitely approached by more numerous draws. Thus nature is apparently "striving to produce the type," but fails only because of the interference of a multitude of accidental causes. The type may therefore be considered the perfect model. Now the only means of discovering nature's type is by finding an average from the

'See p. 78, et seq., infra.

"Pearson, Grammar of Science (Londion, 1900), p. 484, uses a similar phrase, "Nature aims at a type, i. $e .$, selects round it, $c \ell c . "$ 
measurement of many products of nature's art. Hence the average found fairly represents the perfect in physical proportions for the time being.

Just how Quetelet reached the conclusion that the average man represents perifection in mental and moral traits is not equally clear. It seems however to have been reached through manipulation of the phrase "free from excess and defect." This phrase he frequently applied to the average, the excesses and defects being the effects of accidental causes. An excess or defect properly denotes quantitatively more or less of a trait than the average. But the average, as shown in the preceding paragraph, having become in many studies the type of the perfect, an excess or defect readily came to designate too much or too little of a trait, and thus acquired qualitative significance. What he meant by an excess of mental ability or morality or health Quetelet nowhere clearly states. Nevertheless it seems reasonably clear that, in his use of the terms, an "excess" was no better qualitatively than a "defect." Thus he could use the phrase in the most general manner, and, disregarding statistical possibilities, speak of a fictitious average man, having a group of perfectly harmonious qualities, "iree from every excess or defect" and hence the type of perfection of his time."

It is useless here to discuss what may or may not constitute a standard of perfection. Such standards are prone to vary with individual ideals and with the uses to which the qualities considered are to be put. But the following considerations may be brought to bear upon

'Sur thorwme, bk. iv, chap. i, 53 : English translation of same, special preface, p. x; Du Systime social, p. 28, et seq.; Physique sociale. p. 398, et seg. 
Quetelet's position as presented in the two preceding paragraphs. (1) With reference to physical proportions the average may be made a standard of beauty by preliminary definition. (2) If, however, we take Quetelet's objective standard, namely, the type which nature is striving to produce, the average is not the standard of perfection. For, contrary to Quetelet's supposition, the biological type is changing, with the result that nature must be represented as striving to produce not the average height, for example, but a height somewhat above or below the average-a height more favorable to survival and, in this respect also, more perfect. With respect to the average of mental and moral traits as the type of perfection it may be stated, (I) that here, as well as in physical traits, the average gives a tolerably perfect type of the group but by no means the most perfect in the group; (2) that Quetelet seems to have juggled with the phrase "free from excess and defect," using it in two senses; and (3) that average ability or average power in any mental trait is in no danger of being confused with superior grades of ability or power. If it be contended that the perfection of Quetelet's average man consisted largely in the harmony and balance of mental and moral qualities it could be replied not only that the concept of the average man as a composite being having been abandoned as of doubtful utility this contention becomes futile, but also that a man combining only average qualities would be a mediocre person, without intellectual vigor or moral flavor. It might be stated also that theoretically the combination of causes provides that a large group may include one or more individuals possessed of superior grades of abilities, whether physical or mental, all as well-proportioned as in the average of the group. 
It is usual, in criticisms of Quetelet's average man, to point out the inconsistency of viewing him as a type of perfection and nevertheless as somehow endowed with a propensity to crime. But while such a criticism may possibly be apropos, it is an extremely obvious one, and one that neither throws any light on the true nature of the so-called "propensities" nor advances our comprehension of the nature of Quetelet's efforts.

The nature of his studies and the true criticism on the point raised in the preceding paragraph may be brought out by distinguishing the results obtained by different statistical inquiries made by Quetelet. In the first place he distributed the individuals of certain groups on the basis of the normal law for the purpose of finding the average height or average weight of the groups. Such a group might be the entire population of a country, a large group of soldiers, or a large number of persons of a given age. The result obtained was the average height or weight of the groups studied. Quetelet called such a result a quality of the average man, and certainly, if the qualities of the average man are to be determined at all, it must be by such a process. Quetelet always thought of a population group as distributed with reference to every trait, physical, mental and moral, in such a way that the departures from the average "become rarer as they become greater, whether above or below, and so that these variations, both in number and size, are subject to a law which is that of accidental causes." He did not however make such a distribution with reference to any mental or moral trait." A second sort of statistical

'. Sur la statistique morale et les principes qui doirent en former la base," Nowv. mtin., vol. xxi, p. 10.

'On the page cited in the preceding reference he sugkests such a dis- 
studies was that in which certain kinds of social events, as suicides or marriages, occuring in a group viewed collectively, were counted and the average number for a series of years was found. The result was a so-called statistical regularity, indicating the probable number of similar events that would occur in the same group during the succeeding year. Very similar to these were the studies in which Quetelet distributed the number of certain moral acts, as crimes, according to the ages of the persons committing them. He then divided the number of acts by the total number of persons in the respective age groups. The results showed the respective probabilities of committing crime at various ages. These probabilities Quetelet called the "propensity to crime" (penchant au crime)." If these distinctions be sound, it should be evident that the so-called "propensities" to crime, to marry, to commit suicide, as Quetelet found them, are not characteristics of the average man of the group. The average man may have a certain inclination to commit crime, but it is not ascertainable from a study of the criminal registers. The persons committing crime are, with respect to the group average, all on one

tribution with reference to the tendency to marry, and, on page 14 of the same essay, he presents a curve to illustrate the distribution of a population with reference to the propensity to crime, or the probability of committing crime. The actual distribution, however, is not made. Moreover the accompanying discussion shows that his curve actually represents the comparative probability of committing crime at each age. It does not represent the distribution about the average propensity or probability.

'In the "Recherches sur le penchant au crime aux différens åges," Nouz'. mém., vol. vii, p. :7, Quetelet defines the penchant au crime as the greater or less probability of committing crime. Moreover in $D \boldsymbol{u}$ Systime social he suggests as a substitute for the word penchant the word possibilitk. 
end of the curve of distribution, the other end of the curve representing those persons who have an abhorrence of crime, or a propensity to conformity to law. Owing therefore to the prominence given by Quetelet to the concept average man, even in the "Recherches sur le penchant au crime aux différens àges," he may be criticised for not indicating just when he did and when he did not ascertain a quality of this fictitious being.

But far more important than the foregoing was Quetelet's conception of the average man as a biological type. His argument here was very similar to that already presented with regard to the average man as the type of physical beauty.' It rested on the analogy between the distribution about the average and the distribution of the accidental errors. As already shown," Quetelet found in the symmetrical distribution about the average evidence that the average was a type which nature was seeking to produce. Chest measurements of Scotch soldiers and heights of French conscripts were distributed in the same way that the same number of measurements on one person would be distributed, on the assumption that one would in the latter case likely as not make errors equal to the probable crrors of the measurements of chests or heights. Thus, the men of a nation were grouped about their average "as if they were the results of measurements made on one and the same person, but with instruments clumsy enough to justify the size of the variations."

Quetelet's analogy between the efforts of nature in producing a type and of man in measuring a height of a person was in appearance considerably weakened by the

1 Pp. 7:-73 supra.

'Pp. 65-67 supia.

- Du Systime social. p. 18. 
fact that an error of three feet eleven inches in measuring a height of five feet four inches is extremely improbable.' But Quetelet's comparison may be viewed as an illustration of how the distribution of biological measurements in nature may be expected to occur, not as a proof of nature's intentions. Moreover, as Professor Venn has pointed out " the "ideal" series of chance must be distinguished both from the series obtained by measuring a group of homogeneous things and from that secured by many measurements of the same thing. The first of these is arrived at deductively, expressed by the binomial law and remains ever the same; the others are arrived at inductively and vary with conditions. In the case of the third alone does the limit represent a real thing which may be approached indefinitely by multiplying the number of measurements. The type in this case is real and fixed. But in the second case the type is fictitious, and in living things is changing, with the result that measurements continued through a long period of time do not give an indefinite approach to the type.

Quetelet was by no means clear and consistent as to the permanence of the type. He usually spoke of the average man as varying from country to country, as not being the same for urban and for rural populations, as, in fact, being different in different environmental and social conditions. ${ }^{3}$ In other words, "the average man is always such as is comformable to and necessitated by time and place." 4 In direct contradiction to these ideas

'He found the average height of Frenchmen to be five feet four inches, and the extremes, seventeen inches and nine feet three inches.

'Logic of Chance (3rd ed., London, 1888), p. 26, et seq.

'Lellers, p. g6; Du Systeme social, p. 14, el seq.

- Sur l'homme, bk. iv, chap. i, \$3: or, Physigue sociale, vol. ii, p. 391 . 
he stated as his belief that the average physical properties of man have not varied from the earliest times.' He held that plants and animals, subject to the immutable laws of nature, have ever "an unalterable type." "The tree type has remained the same" for the olive since the days of Codrus; even to the size and number of leaves it has not changed." Among plants and animals not only has the average, according to Quetelet, remained the same, but the limits through which variations occur have likewise remained unchanged.' He then introduces still greater confusion by the apparently contradictory statement that man has been able not only to raise his averages but also to restrict the limits of variation, through the acquisitions of science."

It seems impossible to reconcile these various propositions. It is clear from the examples he gives that the last statement does not imply in any way a conscious application of laws of inheritance and biological selection, but merely the effect of the advance of such sciences as optics and surgery in reducing physical defects, and the effect of the spread of knowledge in reducing illiteracy and in raising the average intelligence. As regards changes in the human type, therefore, either in the type itself or the limits of variation about it, the acquisitions of science which Quetelet had in mind, are in all probability ineffective, their effectiveness being dependent upon the extremely doubtful tenet that acquired characteristics are inherited. A partial reconciliation of the other statements of Quetelet regarding the perma-

'Dw Systzme social, pp. 252 and 257: Physique saciale, vol. ii, p. 392.

'Du Systime social, pp. 252 and 257, at sey.

- Ibid.

- Ibid., P. 259; see also Sur l'homme, bk. ir, chap. i. 5 3, or Physipue sociale, vol. ii, p. 396. 
nence of the type may be found in his division of causes into natural and perturbative. He says,

The average height of man is an element which has nothing accidental about it; it is the product of fixed causes which assign to it a determined value.'. . Professions, wealth, climate may cause the development of height among different peoples to vary. Nature and man work together to produce these modifications. I have distinguished these two kinds of action by the names of natural and perturbative forces. The first have a character of fixity and permanence which does not pertain to the second. The latter work as do accidental causes."

Thus, assuming unchanging physical conditions, an unchanging average height would result, while different groups within the same physical environment, selected on the basis of occupations, for example, might have different average heights. So much may be said by way of reconciliation, keeping in mind the analogy of drawing balls from a bowl which served Quetelet as an epitome of nature.

But even this falls short of being satisfactory. If "perturbative" cause act as do accidental causes, then they should not be linked with " natural" causes to explain the difference in the average height of two peoples. If man's action is only "perturbative," and therefore accidental, it could not change the average. But it is interesting to note how very close Quetelet came to the discovery of the selective action of environment. He was only one step from it in his proposition that the average conforms to the necessities of time and place. This statement strongly suggests modification through

'Du Systime social, p. i7.

Ibid., p. 21, et seg. 
change of environment and adjustment to environment. But Quetelet posits unchanged physical conditions throughout recent geologic time' and apparently overlooks the possibility of the migration of a species from one environment to another.

There are other passages in Quetelet which likewise suggest a selective process in nature. These are the passages dealing with asymmetrical distribution, or cases "when the charces are unequal." He found an exception to the general rule of symmetry in the distribution of weights. His limits here were 19 livres and 649 livres, with an average of 140 livres. These limits differ from the average in the ratio of one to four.' But Quetelet passes over this exception to his general rule by insisting that the distribution is continuo:s and that the numbers of individuals above and below the average are the same. In the Lellers ${ }^{3}$ he finds similar sets of observations in the daily fluctuations of temperature in winter, changes in the prices of grain, variation in the mortality rate, and the ratio of the sexes at birth, while barometric pressures extend farther below than above the average. He concludes that "Nature is like man in this -when it differs from its type, it is more often in exaggeration than in diminution." " This is evidence, he says, that the causes tending to produce variation in one direction are stronger or more numerous than those operating in the opposite direction. His illustrative explanation of the condition in nature which the unsymmetrical curve represents is based on the distribution of chances in drawing balls from a bowl in which the white and black balls are not equal but in the ratio of three to

'Du Systzme social, p. 257.

". Letters Xxv and xxvi."
'Ibid., pp. 44-45.

- Du Systema social, p. 113. 
two.' But Quetelet undoubtedly thought of the ratio in nature as "determined and immutable." " Thus, though he used many expressions suggestive of evolutionary change of the type, he did not grasp the notion of such change. ${ }^{3}$ Though he developed and used the method which has come to serve in the work of Galton, Pearson and others as the basis for the mathematical demonstration of evolutionary development, he did not himself make any such use of it.

'Du Systime social, p. 118, et seg.

Ibid., p. 118.

${ }^{3}$ This does not overlook those passages in which he speaks of the progressive development of man's intellectual faculties. In these he refers not to any biological change, but only to the increace in man's command over nature through the growth of scientific knowledge. 


\section{CHAPTER IV}

\section{MORAL STATISTICS}

It has already been stated that Quetelet's studies in moral statistics opened a new field to statistical research, the sphere of human actions, where all is apparently indeterminate and individual. His venture into this field created very wide discussion, especially in Germany, furnished a statistical basis for some of the generalizations in the early pages of Buckle's Histury of Civilization in England, and was significant in the development of the methods, concepts and scope of statistics. The purpose of this chapter is to survey the principles and methods of moral statistics as Quetelet presented them.

By moral statistics is meant that portion of the general science dealing with such individual actions as are commonly classed as moral or immoral. The phenomena usually dealt with are crimes, suicides and marriages. These actions have the characteristics of occurring more or less frequently in a social group, of giving opportunity for the exercise of individual discretion, judgment, will, and of being correlated quite directly with social conditions. Any similar acts would supply data for moral statistics. The first aim is to establish the norms for various kinds of moral actions, that is, the average number that occur under given conditions during a period of time. These norms form the statistical regularities, for it is found that in a series of years the numbers of crimes, suicides or marriages vary about 5251 
their average, showing a tendency for the average number to be repeated from year to year. These regularities are often called statistical or sociological laws. Moral statistics then attempts to correlate the phenomena under investigation with certain physical and social conditions, by showing variations in the numbers as the conditions are changed. To do these things it follows certain welldefined canons and methods. The following pages will present bricfly Quetelet's work and conclusions in this field, and will corsider the nature and value of statistical regularities and the principles of the method followed.

In the "Recherchesstatistiquessurle Royaume de Pay'sBas," Quetelet makes his first study in moral statistics. Aside from the comparisons of France and the Low Countries he studies the ratio of condemned to accused, the distribution of crimes by the age and sex of the perpetrators, and the number of crimes against persons and against property committed by the persons of each age group. This last matter is presented in a table, there being twelve age groups between those under sixteen and those over cighty. In this he gives for the first time a scale of the pencliant au crime for the various age groups, that is, the ratio between the number of persons and the number of crimes for each group. He then compares the numbers for three years under various aspects, emphasizing the remarkable uniformity of the numbers from one year to another. ${ }^{2}$

The "Recherches sur le penchant au crime aux differens ages," ${ }^{3}$ is easily Quetelet's most comprehensive study of crimes. It contains sections on the penchant au crime

'Nouv. mém., vol. v, pp. 25-38.

'Sce quotation, chap. II, p. 55, supra.

'Nouz'. mén.. vol. vii. 89 pages. 
in general, and on the influence of education, climate, seasons, sex and age on this propensity. The distinction of crimes against persons and against property is preserved throughout. At this point we wish to note only his emphasis on the constancy of the numbers from year to year. He places as much confidence in his scale of propensity to crime as in his scale of stature or of mortality.' After pointing out that murders often follow quarrels and other apparently fortuitous encounters, he says, "Nevertheless experience has proven, that not only murders are annually almost in the same number, but even the instruments which are used to commit them are cmployed in the same proportions. . . Thus . . . we pass, etc., as quoted in chapter II. p. 55. And he closes with the famous sentence, "There is a budget which we pay with a frightful regularity; it is that of prisons, chains and the scaffold."

The Sur $l$ komme of 1835 added to the preceding essay a chapter on suicides and duels in the characteristic manner, and several brief articles of 1835 and 1836 in the Bulletins de ' ' academie royale de Bruxelles' were devoted partly to general considerations on the freedom of the will and the regularity of certain social phenomena. So great does he find the constancy in the number of marriages by age groups that in the essay of 1847 he is able to present a scale of the propensity to marry.' and similarly in the essay of 1848 he calculates a scale for

'Op. cit., p. 71; also English trans. of Swr l' homme, p. viii.

Ibid., p. 79.

Ibid., p. 81.

" Sur les maladies des conscrits en France," vol. ii (1835), pp. 277 379: "Sur la justice criminclle en Belgique," ibid., pp. 36s-372: and "De l'influence de l'àge sur l'aliénation mentale et sur le penchant au crime," vol. iii (1836). pp. 180 and 210.

-." Statistique morale," Bnlletin de la com. cent. de stat., rol. iii (1847), especially note pp. 140 and 141 . 
suicides.' In these later studies he repeatedly emphasizes the impressive regularity in the figures from year to year. ${ }^{2}$

It was this emphasis upon the constancy of the social "budgets" which brought upon Quetelet the charge of being a fatalist and a materialist. It was this also which called forth the widest discussion and an abundant literature on the meaning and implications of the regularities revealed by moral statistics. ${ }^{3}$ Quetelet's explanation of this constancy is therefore not without interest. He has nowhere given a formal and thorough discussion of this question, hence it will be necessary to bring together some of his most pertinent ideas.

Quetelet held quite consistently to the proposition that there is no such thing as a real chance occurrence, that is, there is no such thing as an uncaused or unrelated event.4 If events have causes, and the same causes persist from one period of time to another, then the same events may be expected to reoccur. This principle received its first expression in the Recherches statistiques of 1829 in the form, "The same causes persisting we ought to expect the same effects to be reproduced." s "The laws presiding over the development of man, and modifying his actions are in general the result of his organization, of his education or knowledge, means or wealth, institutions, local influences and an endless variety

1 "'Sur la statistique morale," Nouv. mEm., vol. xxi, p. 36.

'See particularly " Statistique morale," p. 143, et seq., where he speaks of the number of marriages as another " budget controlled by the customs and the needs of our social organization."

"See Von John, Geschichte der Statistik (Stuttgart, 1884), pp. 362, et seq.; for a summary of views of many writers on this subject sec Block, Traité statistique, pp. 137, et seg.

'See chap. i, p. 18, supra.

'Page v, and repeated many times, especially English trans. of Sur l'homme, p. vii and p. 6. 
of causes ..." Quetelet lays much stress on the infuence of physical environment and of social conditions and institutions. Man not only possesses individuality, he is also a member of society. "From this point of view, the regularity which we note in the formation of marriages ought to be attributed not to the volition of individuals, but to the habits of this concrete being which we call a people, and which we regard as endowed with a volition of its own and with habits from which it frees itself with difficulty.", "Moral causes which leave their traces in social plienomena are then inherent in the nation and not in the individual." Variations in the marriage statistics of different provinces are due " to moral causes which exist outside of the individual and which are peculiar to each people. These moral causes have not essentially a character of fixity, as have causes in nature, but they fluctuate and vary with time." s

It seems to me that that which relates to the human species. considered en masse, is of the order of physical facts; the greater the number of individuals the more the individual will is effaced and leaves predominating the series of general facts which depend on the general causes, in accordance with which

'Ibid., p. 7: first stated in " Recherches sur la loi de croissance de l'homme," Nowv. minn., vol. vii, p. I of the essay.

Dw Systzme social, p. 8.

". Statistique morale," p. 142.

". Sur la statistique morale," Nowv. m\&m., vol. xxi, p. 6. In "Statistique morale," p. 1:8, he says, " All oceurs as if a people had intended to contract annually almost the same number of marriages and to divide them in the same proprrtions among the different provinces, between city and country, and betwoen bachelors, maidens, widowers and widows."

-. Statistique morale," p. 142; in Sur l' homome, 2 , he says. "The laws which relate to the social body are not essentially invariable; they change with the nature of the causes producing them." 
society exists and main:ains itself. These are the causes we seek to ascertain, and, when we shall know them, we shall determine effects for socicty as we determine effects by causes in the physical sciences.'

This last quotation contains the gist of Quetelet's explanation. General social conditions influencing the greater part of the social group, result in tolerably constant social phenomena, because, according to the law of large numbers, the effects of general causes gradually prevail amidst the multitude of variations due to minute causes.

Several consequences followed, in Quetelet's view, from these principles. In the first place, if the general social conditions act upon man in such an apparently irresistible manner when a social group is observed, then society as a whole must be made responsible for the moral "budgets" due to social conditions.

The crimes which are annually committed seem to be a necessary result of our social organization. . . . Society prefares the crime and the guilty is only the instrument by which it is acromplished. Hence, it happens that the unfortunate person who loses his head upon the scaffold, or who ends his life in prison, is in some manner an expiatory victim for society. His crime is the result of the circumstances in which he finds himself, and the severity of his punishment is perhaps another result of it. ${ }^{2}$

A second consequence is that the sphere of individual freedom is very narrowly limited. Quetelet seems some-

'“Recherches sur le penchant au crime," pp. 80-81 of the essay; see also "Recherches sur le poids de l'homme," p. 10.

"Sur l'homive, last section; English trans., p. Ic\&; sec also p. 6 of the translation. 
times wholly to deny the existence of free will, but, as a rule, he speaks of it as a capricious element acting within a narrow circle of possibilities.' In this view man's will is capable of producing the infinite variety found in individual action, but cannot upset the rules of the social organization. The individual becomes an accidental cause, and its effects mere accidentalities; hence, when a social group is viewed, these effects are neutralized in the same manner that accidental errors are eliminated in making a scries of measurements.

Charged with being a fatalist Quetelet answered by asserting a positive conviction that man can ameliorate his own condition by his own efforts." We have seen that he believed the "moral causes which leave their traces in social phenomena" to be capable of change." Such changes are, in his view, to be brought about through the action of "moral forces" exercised by man in modifying the conditions in which he lives." But tisese "moral forces" are perturbative in their manner of action and the changes they bring about are very slow, like the secular changes in the solar system : for this reason the "moral causes" which predominate in the social system cannot undergo any sudden change.' This perturbative action of man, according to Quetelet, depends upon the exercise of his reason and increases with the growth of

'Sar l'homme, Eng. trans., p. vii: ibid.. "Introductory." 2, p. 6; Dw Systeme sorial, pp. ix, 8. 9, 65. passiom: " Statistique morale." p. 1,36; "Sur la statistique morale," pp. 6. 22 and 35. et seg.

". Recherches statistiques " (18.9). note, p. 25: English trans. of Swr l'homme, p. vii.

Supra, p. 87.

". Recherches sur la loi de croissance," pp. I and 2, and "Recherches sur le penchant au crime." pp. 2 and 80.

-.. Recherches sur le penchant, etc.." p. 80. 
knowledge.' The causes over which man has some control are the social institutions; and since the modification of effects must begin with the modification of causes, the betterment of results must begin with a reform of social institutions." In order that this reform may be carried out with wisdom and intelligence, it should be the part of the statistician, thought Quetelet, to make known, so far as possible, the social effects traceable to special institutions, and the part of the legislator, in the light of this knowledge, to ameliorate social conditions. ${ }^{3}$

The preceding paragraphs make more or less clear Quetelet's explanation of statistical regularities, his deliverances on the question of social responsibility for crime, and his hope for a positive progress as man grows in scientific knowledge. Is his position satisfactory?

Attempted explanation of the regularities of moral statistics has been the cause of much fruitless discussion, because attention has been centered upon the implications that may or may not be drawn with reference to the freedom of the human will. We may avoid this barren philosophical discussion by starting from a principle which makes it impossible and by limiting ourselves strictly to the field of scientific inquiry. It does not seem possible for any science to take any other attitude toward the phenomena with which it deals, than that they are related in direct and complete continuity with

" "Recherches sur la loi de croissance," p. 2.

" De l'influence de l'àge sur l'aliénation mentale et sur le penchant au crime," Bull. de l'acad., ist Scries, vol. iii, p. 185.

"Sur l'homme, bk. iv, final section; Eng. trans., p. 108; "Statistique morale," p. 146; " Sur la statistique morale," pp. 18-19 and 36; " Sur la statistique criminelle du Royaume-Uni. de la Grande-Bretagne. Lettre à M. Porter, à Londres, par M. A. Quetelet," Bull. cent. com. de sla., vol. iv, p. 121 . 
preceding or contemporaneous phenomena. That is, the causal explanation of a phenomenon must be found in antecedent and coexisting conditions where it arises, without resort to some extraneous, unrelated or capricious element. In so far as a phenomenon is a pure accidentality it is not material for scientific inquiry. If any series or group of phenomena of a pure-chance sort were subjected to investigation, no order or relation would be discernible among them. Human reason would be useless and powerless in their presence, and inierence would be impossible. If man's choices were of this sort, psychology would be forever a futile pursuit and education useless and purposeless. To illustrate such a condition by the usual figure of drawing balls from a bowl, one must conceive a bowl to contain a multitude of balls of an equal number of shades of color.' The problem to be solved would be to ascertain from a finite number of draws the probable order of future draws, or the ratio of balls of one shade to those of other shades. Even the largest conceivable number of draws would give no grounds for inference. Under such circumstances we must forever remain in the dark with no guide for our conduct other than unreasoning fear and superstition. The reasoned and ordered knowledge which science seeks is possible only under the assumption that the efficient causes of events are found in antecedent conditions.

This principle of efficient causation must then be extended to the sphere of human conduct. This is where the rub usually comes. The older view of a self with a will extraneous to the motives to action and with a power

'Jevons, Arinciples of Srience (London, 1905). p. 2. refers to Condorcet's expression, "an infinite lottery." 
of fiat regardless of the conclitions of life has generally been discarded. But many, like Quetelet, who give great emphasis to the necessities which the conditions of life force upon us, still reserve a little circle within which this old-time self may disport at pleasure, and exercise its will without let or hindrance. According to the view which we present as the only basis for scientific inquiry, even this little circle and the self, independent of character, motives and conditions, must be given up. This is a completely and frankly deterministic basis. It still preserves that conception of free will which means ability to act in accordance with our own character and motives - the sort of freedom of which all are conscious. Moreover, when it is once seen that scientific knowledge is dependent on their being an order in nan's world, and that true freedom for man is dependent upon the acquisition of a knowledge of that order, it may be added that the deterministic basis makes possible the only freedom that is worth while or even possible for rational creatures.

It seems perfectly sound then to find the explanation of statistical regularities in the persistence of causes. Were we in imagination to reduce society to a state akin to the static state of the economist, in which the internal and external conditions obtaining throughout the population were exactly duplicated from one year to the next, we should not be astonished at the repetition with a dull monotony of the whole gamut of social budgets. But in actual dynamic society, conditions change siowly. Certainly the physical environment does not greatly vary from one year to the next; the physical qualities and the mental traits of the population, and its distribution by age groups, change little in two succeeding years; the social institutions, the customs and beliefs, and knowledge likevise change little. Hence the approximate repetition 
of the numbers of social events from year to year. There will be, for example, about the same number of persons in the population, who by hereditary qualities and experi. ence, are capable of committing murder under certain incentives. From one year to another about the same number of persons thus prepared meet the needed incentives, and the deeds are done. Similarly with the number of stricides, or births or marriages. The explanation is at bottom not dificrent from that of the recurrence of approximately the same number of deaths from year to year.

How then shall the fuctuations in the numbers from year to year be explained? Quetelet seemed to think that these fl:ctuations were the effects of man's free will:- For this reason the average of the numbers for several years shows the effect of general catses, to the exclusion of free will, even, as the true ratio of the balls in the bowl $\mathrm{i}$ : approached as the number of draws is increased. This however must be viewed as an erroncous explanation of the fluctuations. It scems to assume that the causes are perfectly constant, but that the number of persons who capriciously willed to yield or not to yicld to their influence varied. But if the tolerable constancy of results is explained by a tolerable persistence of causes, then the fluctuations must similarly be explained by variations in the causes. The number of causes is extremely large, and the fluctuations in the results are due to differences either in the intensities or in the combi-

'This seems to have been the view also of Prof. Richmond MayoSmith. He says, "With all the regularities there are numerous irregularities which leave room for the freedom of the individual. And it is scarcely possible that siatistics will ever be so perfeet an instrument of investigation as to destroy :hese variations." Slatistics and Saciology (New York, 1895). p. 27. 
nations of the causes. Moreover these variations in the causes, instead of being an evidence of man's free will, are for the most part entirely, as yet, beyond his control. Biological variations in the structure of brain and nervous system, some unknown element in ancestral heredity, may be partially responsible for fluctuations in the rate of suicide; or a crop failure may account for an increase in crimes against property. The point is simply that we cannot assume a causal explanation with respect to the regularities and a fantastic free-will explanation with respect to the fluctuations.

This holds true also of the variations about the mean were the population distributed with respect to some moral trait, as tendency to crime. ${ }^{3}$ Such a distribution would be more or less well represented by the normal law of error, the variations running through all degrees from abhorrence of crime to a keen delight in it. Such a distribution would thus approximate the distribution of chances. Does this not indicate that there is some purely chance or free-will element which makes it necessary to provide for more or less extensive deviations from the type form? The deviations uncoubtedly exist but they are not due to some capricious elcment assumed to exist in each person. The deviations inclicate a freedom on the part of each person in the group to act in

'We may recall here a distinction made in the preceding chapter between those statistical studies which ascertain the so-called social budgets, and those which distribute the members of a social group with respect to some trait, the distribution being assumed usually to be normal. In the preceding paragraph the flictuations from year to year, found by the former kind of studies, were considered. In this paragraph the variations represented by the law of error are considered. Quetclet suggested such a distribution as this for mental and moral traits, but did not actually make any such distribution. See chap. iii, pp. $75-76$, stepra. 
agreement with his character and motives, but even as the location of each chance in a scale of chances is determined by a possible combination of causes, so the location of each person in the scale of distribution is determined by that combination of causes which has determined his character and motives. What that combination is in any particular case may be inscrutable, with the result that particular actions are as unpredictable as the result of a chance draw. But the word chance in this case differs from what we have called pure or absolute chance, in that it is merely a blanket term for our ignorance of and inability to weigh the many minute causes which determine the result. So the variations of the members of a group about their mean, and the location of every member in the scale of distribution are determined by the inscrutable and almost infinitely variable differences in heredity and environment. The differences in natural abilities, in experience, training, education, beliefs, are sufficient to explain, in the scientific sense, the variations about the mode or the mean.

It has often been stated by writers on this subject that the statistical regularities have no compelling power over the individual.' Recall at this point the manner in which the regularity is formed. It is formed by counting the repetitions of a particular moral act during equal periods of time in a population group. The number of suicides in the United States in a series of years would constitute such a regularity. Now what can be meant by the statement that the regularity exerts no compulsion over the individual, that the individual is free but the mass is not, that the rule exists, but the individual may or may not follow it? From the point of view

'See, for example, Mayo-Smith, of. cil.. p. 27. 
adopted in this essay the only possible interpretation is that, whereas there is a high degree of probability that the group as a whole will show about the same number of suicides during the year following, it is impossjble to say what particular individuals will do the deeds. But this is duc merely to our ignorance of the causes ${ }^{3}$ operating in particislar cases. The regularity of moral statistics is in this respect similar to the figures of a mortality table, as has often been pointed out. The inability to predict the death of a given person from the data of a mortality table is no evidence that this person willed not to dic at any particular time we might set. The conditions of life and character determine whether this or that individual shall be numbered among the suicicles. Moreover, from the manner in which the statistical regularity is formed it is evident that the persons contributing to the so-called budget in any year are a small, and, in many cases, a selected group. They are found at one extreme of the curve representing the whole social group. They show the results of particular combinations of causes. The persons represented by the other slope of the curve are in no danger of becoming sticides; their conditions of nature and nurture prevent such a result. It would seem then that the statement that the regularity of the mass exerts no compelling power over the individual is at least unenlightening. It is only a truism or corollary from the method of finding the regularity. A more accurate description is given by the statement that the same causes which produce the regularities do, through differences in their intensity or their

\footnotetext{
'By causes as used throughout this essay is meant simply the antecedent conditions of an act, that is, inherited structure and the impresses of past exprience.
} 
combination, determine the course of the individual; but that only a very small part of the group is subject to those particular combinations of causes, whose effects appear in the regularities. If the statement in question should be interpreted to mean that the individual is not subject to the general conditions of the life of the group in which he lives, then we may invoke the whole body of social science to show that it is distinctly not true.

It is usually assumed as a corollary of the statement considered in the preceding paragraph that the demonstration of the regularities does not disprove the doctrine of free will. This is true if by free will is meant action in agreement with our character and motives, but not true if a capricious element is meant. As already stated, if we explain the regularities by constancy of causes, it is at least inconsistent not to explain the variations by changes in the causes. Furthermore, when it is shown that the regularity changes with a change in the conditions, what other interpretation is possible, than that human action is determined by the conditions of human life?

Similar to the foregoing is the statement that the doctrine of free will cannot be disproven by statistics. With equal facility it might be said, the doctrine can be proved or disproved only by statistics.' If by this doctrine is meant an uncaused cause, a self-originating something without an antecedent but with a consequent, though having only a small circle of activity, then it is certainly true that statistics cannot demonstrate its non-existence. For statistics deals only with groups, and it will never be able to eliminate one cause of group variation after an-

'Quetelet, English translation of Sur l'howme, 5 2, says, in answer to his question "Are human actions regulated by fixed laws," ". Experience alone can with certainty solve a problem which no a priori reasoning could determine;" also Du Systime sorial, p. 65. 
other, and correspondingly reduce the group, until the individual is reached. The causes of variation are practically innumerable, and to attempt to eliminate them one after another to see whether a final capricious and unaccounted-for element remains is not only impossible but would be unending were it possible. If however the doctrine means only that we are able to do this or that if we wish to do it, then it is not at all in conflict with the explanation of statistical regularities here set forth. For this would simply mean that our character and motives determine our actions-character and motives being themselves products of the past brought into contact with present stimuli.

Are the statistical regularities of such a nature as properly to be called social laws? Quetelet seems to have thought that his regularities were social laws comparable to the laws of physics. He speaks frequently of the social system in such terms as suggest the Systeme du monde of the astronomer. After defining the average man as analogous to the center of gravity in bodies, he says," If we wish in some way to establish the bases of a social mechanics, it is he whom we ought to consider, without stopping to examine particular or anomalous cases." " In the Recherches sur le penchant au crime ${ }^{2}$ he states that the average man will undergo modification in time. It should then be determined

whether these modifications are due to nature or . . . to certain forces, of which man disposes according to his free will. . . The science which would have for its object such a study would be a true social mechanics, which, no doubt, would

'Recherches sur la loi de croissance de l'homme," p. 4.

"Page 2. See also "Recherches sur le poids de l'homme," pp. 10, $I 1$ and 12. 
present laws quite as admirable as the mechanics of physical bodies, and would bring to light principles of conservation which might be perhaps only analogous to those which we already know.'

He often repeated the statement that the results obtained by viewing a large group of men were of the order of physical facts." In the Letters' he says:

This great body (the social body) subsists by virtue of conservative principles, as does everything which has proceeded from the hands of the Almighty..... When we think we have reached the highest point of the scale we find laws as fixed as those which govern the heavenly bodies: we tum to the phenomena of physics, where the free will of man is entirely effaced, so that the work of the Creator may predominate without hindrance. The collection of these laws, which exist independently of time and of the caprices of man, form a separate science, which I have considered myself entitled to name social physics.

In the first place it is doubtless an exaggeration, or an inaccuracy to speak of the regularity itself as a statistical or social law. The average number of suicides in Belgium, for example, merely acquaints us with a social fact. Such a fact is itself variable and has only a greater or less degree of probability of being repeated in the succeeding year. Such a fact however becomes the basis of more or less inclusive social laws when relations of coexistence and sequence are established between it and the conditions in which it arises. The establishment of such relations will of course pass through all the stages

'Page 2. See also "Recherches sur le poids de l'homme," pp. 10, 11 and 12.

'See supra, p. 87. 'Page 178. 
from hypothetical generalization to more or less exact quantitative statement. Changes in the fact thus become clearly and even quantitatively correlated with changes in its conditions. But while both the statistical fact and the social laws found through its correlations have considerable scientific value, when tested by their usefulness in prevision, such value is not so great as that of many of the laws of astronomy and physics. In the case of these latter, inferences have a degree of assurance only slightly removed from certainty, owing to the completeness of the induction, the permanency and simplicity of conditions and the facility with which effects attributable to a certain condition or to certain conditions may be isolated. But in the statistical study of social phenomena the complexity and variability of conditions and the very great difficulty of isolating the effects of particular causes give to inferences from established causal relations to future events more or less uncertainty. Not only do we not know with exactness the influence to be attached to each one of the conditions essential to the production of a social event but we do not know the proportions which will persist among the conditions themselves. Thus it may be shown that the marriage rate in England tends to vary directly with the amount of foreign trade per capita of the population, " but a quantitative statement of the degree of change in the former following a specified change in the latter can be made only with a considerable margin of error. This is because the influence of the amount of imports and exports (or any other index of industrial activity) on the marriage rate cannot be sufficiently isolated from other

'A. L. Bowley, Elements of Statistics (2d ed., London, 1902), pp. 174, et seg. 
influences, such as age grouping of the population, standards of living and social customs. It is also due to the fact that all the conditions determining the marriage rate, and consequently the marriage rate itself, change more or less rapidly from decade to decade.

It does not seem probable therefore that social laws derived from the study of the regularities of moral statistics will ever become sufficiently general to be "independent of time and the caprices of man," as Quetelet expected. Even the law of mortality changes slowly with succeeding generations. But concrete social phenomena change from place to place and time to time and may come quickly into vogue and as quickly disappear. Not only are there variations about the average result for a series of years but the type itself changes with its conditions. Quetelet's hope of arriving at statistical laws independent of time and place was based apparently on his assumption of constant causes. He always spoke of the average as resulting from such causes and hence iree from the effects of variable and accidental causes. But yet he believed man capable of bringing about secular changes in the social budgets.' Quetelet however did not reconcile these conflicting notions," nor did he anywhere demonstrate the existence of a constant cause. Were the types of social phenomena the results of really constant causes, then their true values could be indefinitely approached by more and more observations. But the average keeps shifting in obedience to the changing conditions of dynamic social life. The illustration of drawing balls from a bowl in

'See pp. 87 and 89 . supra.

- For the same conflict with reference to the Average Man, see chap. iii, p. 78, et seq.. supra. 
which are an infinite number of white and black balls in a fixed or determined ratio, which may be forever approached, is not true to the conditions in society. The ratio must be represented as changing slowly. While therefore holding to the mechanical nature of social causation, which was fundamental in Quetelet's view, the problem of discovering or verifying social laws by a statistical process must be made immensely more difficult than he ordinarily represented it to be. For the want of the concept of evolutionary change Quetelet's social physics did in fact provide only for a "social statics." To this must be added the more difficult sphere of "social dynamics." Not only must the statistical regularity be correlated with certain dominant social conditions, but the order of changes in the regularities themselves as correlated with developing social life must be discovered and epitomized in the form of scientific law.

The preceding paragraph makes it unnecessary to emphasize a point made much of in Venn's Logic of Chances that, inasmuch as the type in moral statistics is constantly changing, not only can it not be indefinitely approached by long-continued observation, but it may be even missed altogether if statistics are collected through so long a time that the results arise under different sets of circumstances.

It remains in this chapter to state certain basic principles of procedure followed by Quetelet in the study of the moral actions of men. In estimating the physical qualities of men; some, as height and weight, may be measured directly, while others, as strength, can be appreciated only by their effects. It is not absurd to say that one man is twice as strong as another with respect

'Second edition (London, 1876), pp. 15, 16 and 83 to 89 . 
to pressure of the hands, if this pressure applied to an obstacle produces effects in the ratio of two to one, conditions being the same for the two men.' Similarly in the appreciation of man's moral and intellectual traits it is necessary to admit as fundamental that "causes are proportional to the effects produced by them.". Thus, from a study of actions, literary products, or other effects which may be attributed to the presence of a particular mental or moral trait, there is sought a knowledge of the trait itself. This principle was probably derived by Quetelet from the principle of probabilities that the ratio of white to black balls in an urn is that shown by many drawings. Quetelet applied it in the measurement of certain mental and moral traits at different ages. in the same way in which it would be used by the psychologist in the study of mental traits and abilities. This principle is however precisely the same as that which must be used by the sociologist in the inductive study of "types of mind" and "types of character" of a population.3

The second principle posited by Quetelet is one that is essential to all statistical inquiry, namely, that reliable results can be obtained only by the study of many rather than few individuals. It is the group rather than the individual upon which attention must be centered. It is only thus that any order or generality can be ascertained amidst the apparently chaotic diversity that is so bewildering when the members of a social group are viewed singly. Here again we meet with a principle derived from the study of probabilities, namely, "that many in-

". Recherches sur le penchant au crime," p. 6.

- Jbid., p. 7. " Sur la statistique morale." p. 7.

'Giddings, Inductive Sociology (New York, 1901), chap. ii. 
dependent disturbing causes of small individual effect neutralize one another in the mass.", To these two general principles might be added many particular ones derived from Quetelet's discussion of the necessity of comparability of data, of the extent to which small diversities in the data may be neglected when the numbers are large, and of the incompleteness of the records of moral actions." .

It is possible to make a number of criticisms of Quetelet's results, both in the study of the development of dramatic talent and in the study of the penchant au crime by ages. Suffice it to say that he was inclined to make an exaggerated use of the second principle noted above. He relied too much on mere multiplication of instances to overcome divergences in the instances themselves. ${ }^{3}$ But such criticisms by no means affect the validity of the general principles of his procedure. A scale of penchant au crime derived from the mere number of crimes by age groups, without regard either to the differences in the gravity of the crimes or to the varying proportions in which different kinds of crime are detected, ${ }^{4}$ would not be thoroughly accurate. But this means only that attention must be given to these causes of error. To study man's nature from the manifestations

${ }^{1}$ Bowley, op. cit., p. 263.

'See “ Recherches sur la Roy. de Pays-Bas," pp. 29-30; “ Recherches sur le penchant au crime," pp. Io and 17, et seq.; Bull. de l'acad., vol. ii, note p. 370 ; Letters, p. 219 , et seq., and especially the first pages of "Sur la statistique morale."

"That he was not unaware of the error here involved is shown by his statements in Sur l'homme, bk. iii, chap. i, \$3, fourth paragraph.

- A larger proportion of crimes of violence are detected and brought to justice than of petty thefts. Since therefore crimes of violence, by Quetelet's tables, are more numerous at ages $21-25$ and $26-30$ than at others, the scale based on numbers only is unduly large for these groups. 
of that nature, to study social conditions by means of their products, and to study groups rather than individuals in order to neutralize individual peculiarities are not only valid but absolutely indispensable in statistical research.

It is thus in Quetelet's studies of the moral actions of men that is to be found the basis of the quantitative study of social life. The Berlin Academy of Science and Nám Reichesberg doubtless exceeded strict accuracy in hailing Quetelet as "the founder of a new science," "social physics," or "sociology." " Sciences pass through various stages before they become quantitative. As the true pioneer in the field of moral statistics, however, he formulated and applied with impressive effectiveness the method of rescarch which is especially appropriate in sociology and economics. It does not seem at all impossible that the social sciences may one day approximate the exactness of the physical sciences. Quetelet would then appear as the most conspicuous among the early workers in the field of exact social science, and as the first formulator of the quantitative method in the study of social phenomena. The demonstration of those regularities in human actions which evidence the presence of law, and the formulation of the method for their discovery were immense contributions to man's knowledge of and power over his world. Though Comte used both the words social physics and sociology, he did not succeed in formulating a method of investigation. This was done by his scorned " contemporary, Quetelet.

'Sec chap. i. p. 33, supra.

-Auguste Comte, Cours de philosophie positize, (4th ed., Paris, 1877). vol. iv, p. 15, note. 


\section{CHAPTER V}

\section{STATISTICAL METHOD}

In the preceding chapter it was stated that Quetelet's main contributions to social science were his demonstrations of and insistence upon the regularity and order in social phenomena and his formulation of a method for discovering this order. The exaltation of statistics into an exact instrument of observation was more uniquely his service than his contention that there are laws of human action and social life. The latter was by no means a new doctrine-even the inductive study of statistical regularities had been more or less steadily carried on since the days of Graunt's Observations. But no one before Quetelet saw so clearly as he that the basis of the method of observation in the biological and social sciences must be founded on a general characteristic of social phenomena themselves, namely, their variability about type forms. This variability is in fact a very general characteristic of all observations in which counting or measuring is resorted to. Whether in estimating the height of an animate or inanimate object from many measurements, or the average height of a group of like things, as a group of men, whether we seek the reaction time of a single individual or of a group of individuals there is found a variation of the results about the average or type. Quetelet's conception of the average man was based on the doctrine that in all that relates to social groups there will be found this variability about the 106 
group average. His statistical method therefore became a search for averages, for the limits of variation and for the manner in which this variation, under ordinary conditions, would occur. It was his general supposition that the distribution about the mean would agree with the distribution of probabilities shown by the probability curve. The first step in the presentation of his method will therefore be an exposition of the derivation of his probability scale, and its use in the study of averages and deviations. Then we shall pass to Quetelet's classification of causes and his methods of locating them.

On its theoretical side Queteiet's statistical method was the outgrowth of an application of certain principles of the theory of probabilities to his researches. Such application is shown in a general way throughout his earlier works in his insistence upon the study of groups, or the employment of large numbers of observations, in order to allow the effects of accidental causes to neutralize themselves; in his statement that "the precision of results increases as the square root of the number of observations:" " and in his suggestion of the use of the probable error in determining the value of data.' But his ideas were not given systematic treatment previous to the essay Sur l'appreciation des documents statistiques, et en particulier sur l'appreciation des moyennes.'

In the first part ' of this essay he classifies causes as constant, variable and accidental, and shows by examples how to detect their presence and how to eliminate the

'Sur thomme, bk. iv, chap. ii; English translation, p. 105.

'lbid., p. 103.

- Bulletin de la commission centrale de statistigme, vol. ii (1845), pp. $205-286$.

-. Première partie. Appréciation générale des causes et de leurs tendances." 
effects of periodically variable and of accidental causes. ${ }^{3}$ In the second part "he sets for himself the problem of determining "the degree of energy and the mode of action" of these causes. As introductory to this he inquires into the probability of results under various suppositions. In the first place, ${ }^{3}$ he supposes the number of chances to be known, and to be rigorously equal to each other. The probability of the desired result is then expressed by a fraction having as its numerator the number of chances favorable to the event, and as its denominator the total number of chances. Thus, in clrawing a ball from an urn containing three white and one black balls, the probability of drawing a white ball is $\frac{3}{4}$. The probability of drawing a black ball is ${ }_{4}$, and the sum of these two probabilities is unity, the symbol of certainty. If the urn contain an infinite number of white and black balls in equal numbers, the probability of drawing a white ball is $\frac{1}{2}$. In a few draws the ratio of the white to the black balls drawn may vary considerably from their ratio in the urn, that is, may be now too large and now too small, owing to the action of many accidental causes; but in a large number of trials there will be drawn almost as many white as black balls. This is due to the fact that the true ratio of the balls in the urn acts as a constant cause, giving to balls of each color the definite probability of one-half.

Quetelet supposes, secondly, that the number of chances is unknown. ${ }^{4}$ In this case one knows neither the colors of the balls in the urn nor the ratio of balls

'See infra, p. 129, et seg.

" Deuxième partie. Appréciation mathématique des causes et de leurs tendances."

'Ibid., § ii; Letters, p. 7, et seq.

‘Ibid., § iii. 
of one color to those of another. But by repeated drawings one can determine both of these unknown facts. The precision of the ratios thus found, or their approximation to the true ratios, "increases proportionally to the square root of the number of trials." "But the urn we interrogate is nature." - Thus, if one asks what is the ratio of male to female births, it is necessary to bring together the results for a series of years. The number of male births for every one thousand female births is found to vary in Belgium, 1834 to 1842 inclusive, from 1055 to 1076 , with an average of 1065 to 1000. This ratio in nature is comparable to the fixed ratio of white to black balls in the urn; and in either case the true ratio is approached more and more closely as the data increase.

In the third place Quetelet inquires into the law of possibility when the number of chances is limited; that is, when the number of chances is small, how are they distributed? If the balls are drawn one at a time from an urn containing an equal number of white and black balls, it is clear that there are two equal chances, either a white or a black ball may be drawn. The two chances are divided equally between the two possible results or in the ratio of $1: 1$. If we wish to speak in terms of probabilities, instead of chances, we may say that either result has a probability of $\frac{t}{t}$. The sum of the probabilities of drawing a white and of drawing a black ball is therefore $t+\frac{t}{2}$, or unity.

Suppose next that from a long record of draws made one at a time, we unite the first and second, the third and fourth, the fifth and sixth, and so on, and that we represent white by $a$ and black by $b$. The first one of

'Mid., D. 230.

'See also Letlers, p. 10. 
the two balls drawn may be equally either $a$ or $b$, and likewise the second may be equally $a$ or $b$. If the first be $a$, the result of adding the second may be either $a a$ or $a b$, and if the first be $b$, the result of adding the second may be either $b a$ or $b b$. All four of these results, $a a, a b, b a$ and $b b$ are equally probable. Since however $a b$ and $b a$ are alike in composition, each being composed of one white and one black ball, there are in reality only three possible combinations, namely two white, one white and one black and two black, or $a a, a b$ or $b a$, and bb. Among these three combinations the four chances are distributed in the order $1,2,1$, or in the order of the coefficients in the expansion of $(a+b)^{2}$ or $a^{2}+$ $2 a b+b^{2}$. If now we inquire as to the probability of each of the combinations, we note that $a a$ has one out of the four equal chances, $a b$ (or $b a$ ) two out of the four and $b b$, one out of the four; therefore their respective probabilities are $\frac{1}{4}, \frac{2}{4}, \frac{1}{4},{ }^{3}$ the sum of which again gives unity. The probabilities may be obtained directly by expanding $\left(\frac{1}{2}+\frac{1}{2}\right)^{2}$.

At the risk of tediousness the demonstration may be carried one step further, by supposing the draws to be taken in groups of three at a time. To each of the four equally likely results obtained by taking them two at a time will thus be added $a$ or $b$. There is thus obtained eight equally probable combinations, namely $a a a, a a b$, $a b a, a b b, b a a, b a b, b b a$ and $b b b .^{2}$ Out of these eight,

'In the article “'Sur l'appréciation, etc.," Quetelet does not touch upon the probability of a compound event. But in the Letters ("Letter vi") he shows that the probability of a compound event is equal to the product of the probabilities of the simple events composing it. Thus in the case just noted, the probability of drawing $a$ or $b$ is $1 / 2$; hence the probability of drawing $a a, a b, b a$ or $b b$ is $1 / 2 \times 1 / 2$ or $1 / 4$.

2 From the preceding note it is clear that the probability of any one of these eight combinations is $(1 / 2)^{3}$. 
only one contains all white or all black, while three contain two white and one black, and three contain two black and one white. There are thus four different combinations, $a a a, a a b, a b b$ and $b b b$, and the eight chances are distributed among them in the order 1, 3. 3, 1, or in the order of the coefficients in the expansion of the binomial $(a+b)^{3}$. The probabilities of the four combinations are evidently $\frac{\hbar}{b}, \frac{t}{2}$ and $t$, or the results obtained by expanding $\left(t+\frac{1}{2}\right)^{3}$, the sum of the probabilities being here, as always, equal to unity. If taken four at a time, there are five different combinations, among which are distributed sixteen equal chances in the order $1,4,6,4,1$ or the coefficients of $(a+b)^{4}$. Moreover the probabilities of the five combinations are $\frac{1}{6}, 18$, is. if and $\frac{1}{2}$ respectively, or the results given by $\left(\frac{1}{2}+\frac{1}{2}\right)^{4}$.

From these examples it appears that the distribution of the chances of the various combinations follows the order of the coefficients in the successive powers of the binomial expansion, or the series given by the successive lines of the arithmetic triangle.' There is in every case a perfectly symmetrical distribution of chances on either side of the most probable combinations. It must not however be supposed that the various combinations will, in actual experiment, be drawn in the proportions indicated by theory. Many accidental causes lead to fuctuations of the experienced distributions about the theoretical distribution; but in the long run these fluctuations are neutralized so that by a sufficient number of draws the actual distribution of the frequencies of the combinations can be made to approach indefinitely the theoretical distribution."

'Quetelet presents this triangle (ibid., p. 235. and Lotsers, p. 60) up to the 13th line. See Jerons. Principles of Srience (London, 1005). p. 182 , et seq.

'Loters, pp. 35-36. 
Quetelet next tests this agreement between theory and experience by making 4096 draws, one ball at a time, from an urn containing forty white and forty black balls. Each draw is registered and the ball returned to the urn. The results are then studied to determine the proportion of black balls in all the possible combinations, when the draws are grouped two at a time, three at a time and so on up to twelve at a time. He also tests with satisfactory results the validity of the principle that the precision of results increases as the square root of the number of draws.

In the fourth place Quetelet inquires into the laws of possibility (or the scale of the distribution of chances) when the number of chances is unlimited. He states that

when we interrogate nature, the number of chances is generally presented to us as unlimited, that is to say, one must conceive that each group which is drawn from the urn may be composed of an infinite number of balls, and that, consequently, the number of groups may be likewise unlimited, and may present white and black balls in every imaginable combination.

But since the number of trials with which one deals in experience is always relatively limited, and since one can neither actually conceive nor calculate an infinite series, Quetelet believes all practical purposes will be served by the probabilities of the rooo combinations that are possible when 999 balls are drawn at once from a bowl containing a multitude of white and black balls in equal numbers. The total number of chances in this case is represented by a number composed of more than three

1".Sur l'appréciation, elc.," 2nd part, $\S \S$ vi and vii.

Ibid., § viii. 
hundred figures. Since in all these chances there is only one of drawing all 999 balls of one color, such a result may be viewed as impossible. All the combinations having more than 549 balls or fewer than 450 balls of one color, whether white or black, have all together little more than one chance in one thousand, while all those combinations having more than 579 balls or fewer than 420 balls of one kind, have scarcely one chance in ten million. Hence it is useless to consider the probabilities of combinations beyond these latter limits.

Quetelet then presents a table (see Table $A$ on the next page) showing the probabilities of drawing each of the combinations from the most probable one of 499 white and 500 black to the scarcely probable one of 420 white and 579 black.' Each of these eighty groups is paralleled by an equally probable one in which the colors are interchanged. Alongside of the scale showing the probability of each combination is a table (Table B) which gives the "scale of precision," or the sum of the probabilities beginning with the most probable group, and a table (Table C) giving the relative probability of drawing each group. Each combination is ranked, the most probable combination being rank one. The first twenty-two ranks of this scale are presented herewith."

1.' Sur l'appréciation, etc.." pp. 244-245.

- For the complete table see Letters pp. 256-258: Bowley, op. cil.. p. 273 gives Table $B$ and Table $C$ for the eighty ranks. 
Scale of Possibility and Precision

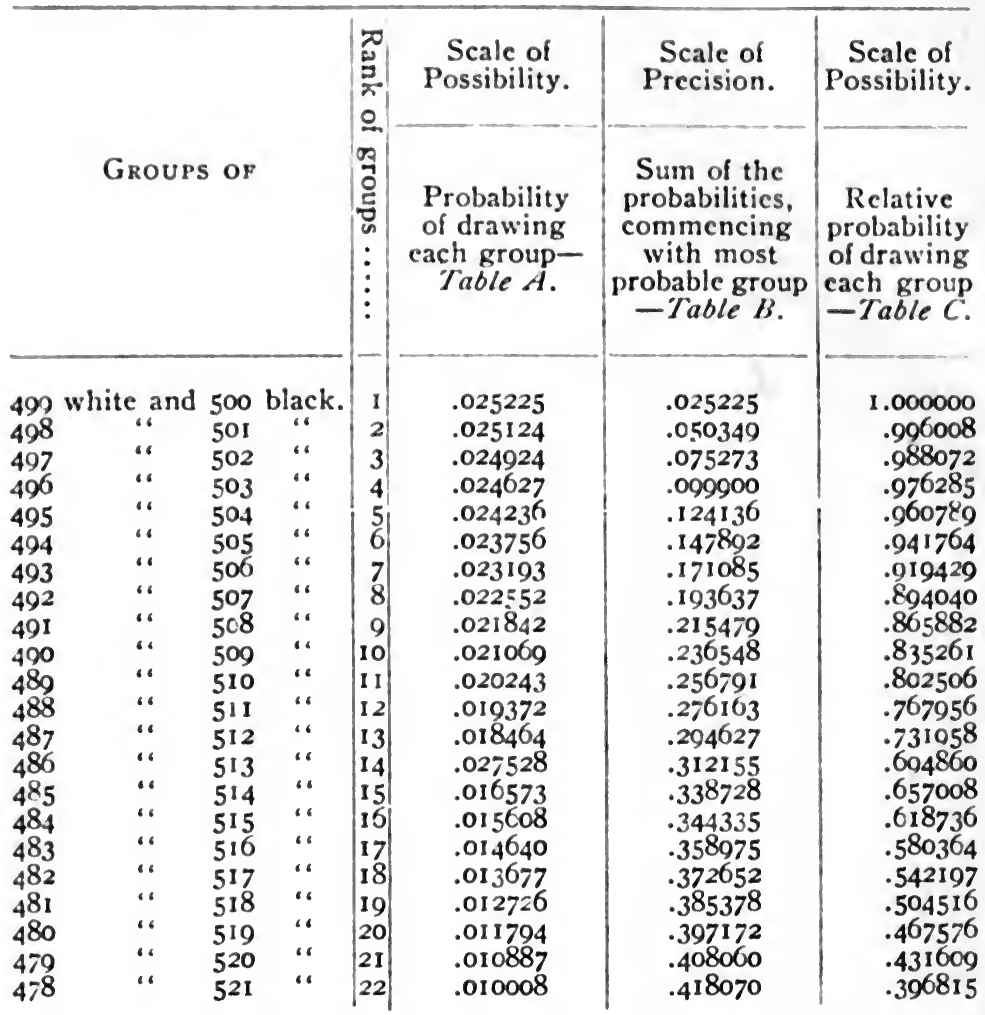

In deducing this scale Quetelet first found Table $C$. $^{\prime}$ As already shown the number of chances of any combination is given by its coefficient in the binomial expansion. If one represents the probability of the most frequent combinations by unity, the relative probabilities of other combinations with respect to unity may be readily

'Ibid., "Addition," p. 274, et seq.; Letters, " Notes," p. 259, et seg. 
found. Now the coefficient of the general term in the development of the binomial is

$$
m(m-1) \frac{(m-2) \ldots(m-n+1)}{1.2 .3 \ldots m}
$$

and the term immediately following is

$$
m-\frac{(m-1)(m-2) \cdots(m-n+1)(m-n)}{1.2 \cdot 3 \ldots(n+1)}
$$

These coefficients show the respective chances of two succeeding combinations. Their ratio is as $1: \frac{m-n}{n+1}$ If therefore the probability of the most frequent combination is represented by unity, the probability of the immediately succeeding combination becomes $\frac{m-n}{n+1}$. Moreover the coefficient of any term being known, the coefficient of the succeeding term may be found by multiplying the known value by $\frac{m-n}{n+1}$. It must be noted that $n$ is always one less than the number of the known term. In drawing 999 balls at a time the most probable combination is 499 of one color and 500 of the other. This term in the series would be either the jooth or the 50rst; as however Quetelet works with the second half of the symmetrical series, he begins with the 501st term. Representing its probability by unity, the probability of the succeeding combination, that is, 498 white and 501 black, becomes $\frac{999-500}{500+1,}$ or $\frac{499}{501}$. This reduces to .996008 . This is also the relative probability of drawing 498 black and 501 white. The probability of drawing 497 of one color and 502 of the other becomes $\frac{499}{501}$ 
multiplied by $\frac{m-n}{n+1}$ or $\frac{499}{501} \times \frac{498}{502}$ By this process were found the successive values of Table $C$.

Table $A$ is next deduced. Designating by $a, a^{\prime}, a^{\prime \prime}$, etc., the successive values of Table $C$, and their sum by $\Sigma a$, Quetelet states that the absolute probabilities of Table $A$ result from the divisions indicated by $\frac{a}{\Sigma a}, \frac{a^{\prime}}{\Sigma a}$, $\frac{a^{\prime \prime}}{\Sigma a}$, etc. Quetelet's description of his procedure is not quite accurate at this point. The values of Table $A$ are in fact found by the following divisions: $\frac{a}{2 \Sigma a}, \frac{a^{\prime}}{2 \Sigma a}, \frac{a^{\prime \prime}}{2 \Sigma a}$, etc. The result of dividing each of the relative probabilities given in Table $C$ by their sum is that the sum of the quotients thus obtained is equal to unity. This would mean that the sum of the absolute probabilities of one-half of the combinations should be considered equal to unity. But since the symbol of certainty is unity, the sum of the probabilities of one-half of the combinations must equal .50 , as Table $B$ indicates. Hence the individual relative probabilities must be divided by twice their sum in order to get the absolute probabilities.

From Table $A$ is found Table $B$ by adding the successive values. The sum of the probabilities as given for eighty ranks in Table B, amounts to .4999992 . Doubling this, so as to include the probabilities of the parallel groups, gives .9999984 . As unity represents certainty, the difference between one and .9999984 or .0000016 represents the total probability of all combinations beyond 579 of one color and 420 of the other.

"“Sur l'appréciation, etc.," p. 275; Letlers, pp. 260-26r. 
The distribution of the chances or probabilities for fifty combinations on each side of the most probable combinations is then presented graphically.' The respective probabilities are represented by rectangles, which by their relative sizes show the rapidity with which the probabilities diminish. Assuming that in nature the accidental causes of variation are infinite in number, and that consequently "events vary through infinite and imperceptible degrees," it is necessary. in order accurately to represent nature, to conceive the number of rectangles to be indefinitely increased and their width indefinitely diminished, until the lines joining their tops merge into a continuous curve. This curve is the curve of possibilities (courbe des possibilites). It shows the distribution of chances when their number is unlimited. Quetelet deduces the value of the mean term, or coefficient of the most probable combination when the number of terms is infinitely great, the probability of this term, and the formula for the curve of possibility itself.3 He also makes a comparison between his scale, "calculated on the basis of a thousand different events," and that given by Cournot, "in which the probability of the expected event may pass through every possible gradation." He finds that one rank of his table corresponds closely to four and one-half ranks of Cournot's table.

Throughout the foregoing development Quetelet continually assumed that the chances were equally favorable

".Sur l'appréciation, elc.." ix, and chart at end of that essay: Letlers. p. 68.

'Ibid., p. 249.

'Ibid., p. 276, et seq.; Letlers, p. 263, et seq.

- Hbid., p. 280, et seq.; Letlers, p. 255, et seq. 
to white and black balls. On this assumption he gets, in theory, the perfectly symmetrical distribution of chances shown by the coefficients of the binominal expansion. Moreover, this hypothesis provides for the occurrence of combinations farthest removed from the most probable one. Theoretically there is an infinitesimal probability for the combination having an infinite number of balls of one color. But, as Quetelet points out,' these extremely small probabilities may be neglected. When he comes to test the agreement between theory and practice ${ }^{2}$ he finds that even in drawing as few as ten, eleven or twelve balls at a time, he does not get, in several hundred draws, a single combination of balls all of one color. Thus in experience the extreme combinations do not occur if the number of possible combinations is very great.

Quetelet passes next to the application of his law of possibility to scientific observations. This application involves Quetelet's theory of means. He says, "the theory of Means serves as a basis to all sciences of observation." 3 "In all things to which plus or minus may be applied, there are necessarily three things to consider, -one mean and two extremes." " "Means properly so called " are to be distinguished from "arithmetic means." 5 Their difference was not in the process by which they are found, for both are found by the method of finding an arithmetic average, but rather in the nature of the observations from which they are derived. The average of many measurements of the height of a certain house would give a true mean, while that of the heights of the

"“Sur l'appréciation, etc.," p. 243; Letters, pp. 66-67.

"Ibid., \$§vi and vii; Lellers, pp. 62, 25i-255.

"Letlers, p. 38.

'Ibid., p. 39.

"Ibid., "Letter xi." 
houses on a given street would be only an arithmetic mean. Many measurements of the same thing are bound together by a "law of continuity," "they are grouped about their average "in a determinate order, which is that assigned by the scale of possibility." It was one of Quetelet's most important discoveries that the measurements of the height or other physical trait of a group of men were likewise grouped about their average. Thus the average height, as represented by the average man, is a true mean.

Quetelet's law of the distribution of chances must first be related to the distribution of a set of measurements of the same thing about their mean and then to the distribution of biological measurements. ${ }^{3}$ We deal then first with the errors of the measurements. Quetelet did not define the term error. It may be defined (I) as the difference between the true value sought and any measurement or (2) as the difference between the average and any measurement. As the average approaches the true value through more and more measurements, the two definitions finally coincide. Quetelet made no systematic statement of the hypotheses underlying the theory of the distribution of errors, but they may be found, expressly or impliedly, in his work. They may be stated as follows :

(I) The average of a series of measurements repre-

'Lellers, p. 42.

'/bid., p. 77: " Sur l'appréciation, elc.," p. 250.

- Quetelet speaks indifferently of the distribution of errors and the distribution of measurements; and while of course the former distribution determines the latter, it is to the distribution of errors that the distribution of chances by the binominal law is assimilated.

- See Mansfield Merriman, A Text-book on the Method of Least Squares (3rd ed., New York, 1888), p. s. 
sents an approximation to the true value sought." Theory indicates that the precision of this approximation increases as the square root of the number of observations. ${ }^{2}$

(2) The causes of the errors are called accidental causes. They are very numerous, even infinite in number; they act independently of each other; each is of small effect. ${ }^{3}$

(3) These causes are equally favorable to excess and to defect. "Each of the accidental causes... has the same probability of acting in one direction as (in) the other. This probability is then $\frac{1}{2} . " 4$ This is the same as the probability of drawing a white or a black ball from a bowl containing an equal number of balls of each color. For this reason the errors resulting from the various combinations of many accidental causes of error will be distributed according to the binomial law. From this it follows both that the errors are symmetrically distributed about the mean and that "small errors are more numerous than large ones," ${ }_{5}$ or as Quetelet phrases it, the greater number of observations "occur in the immediate neighborhood" of the mean, and "the further we depart from the mean, the fewer observations will each group include." 6

(4) Though the theory provides for errors of any amount, there are always more or less narrow limits beyond which errors do not occur.

${ }^{1}$ Letters, pp. 72, 76, 90.

"Ibid., p. 36, and "Letters" xvi and xvii.

s'lbid., pp. 22, 107, 108, et seq., passim.

'Ibid., p. 280; see also pp. 77-78, 84 .

'Merriman, op. cit., p. 15.

'Lelters, pp. 77, 90; “Sur l'appréciation, elc.," p. 250. 
By very similar principles to the foregoing the law of the distribution of chances may be related to the distribution of biological measurements. In this case the average is an approximation to the group type. There are assumed to be a vast number of minute independent causes of deviation from the type or average, equally favorable to excess or deficiency of development. Finally small deviations are most numerous, the deviations become less numerous as they become larger, and there are limits beyond which deviations from the type do not occur in nature. Thus the Average Man becomes the type, about which all other men of a homogeneous group are distributed according to a definite law.

It was in the foregoing manner that Quetelet transformed the law of the combinations of two independent events when the number of chances is very large, that is the binominal law, into a law of error, and then made this latter serve as the law of distribution of variations among living things.

In testing the fit of a series of measurements to his scale of precision Quetelet usually made use of a table consisting of nine columns. '

The following example, showing the distribution of the chest measurements of 5738 Scotch soldiers, serves better than any other from Quetelet's writings to illustrate the process involved:

'See "Sur l'appréciation, etc.." pp. 251, 252, 255. 259, 260; Letlers. pp. 85, 88, 276, 277; and Bowley, Elcmiculs of Statistics (2d ed., London, 1902), pp. 278-279. 


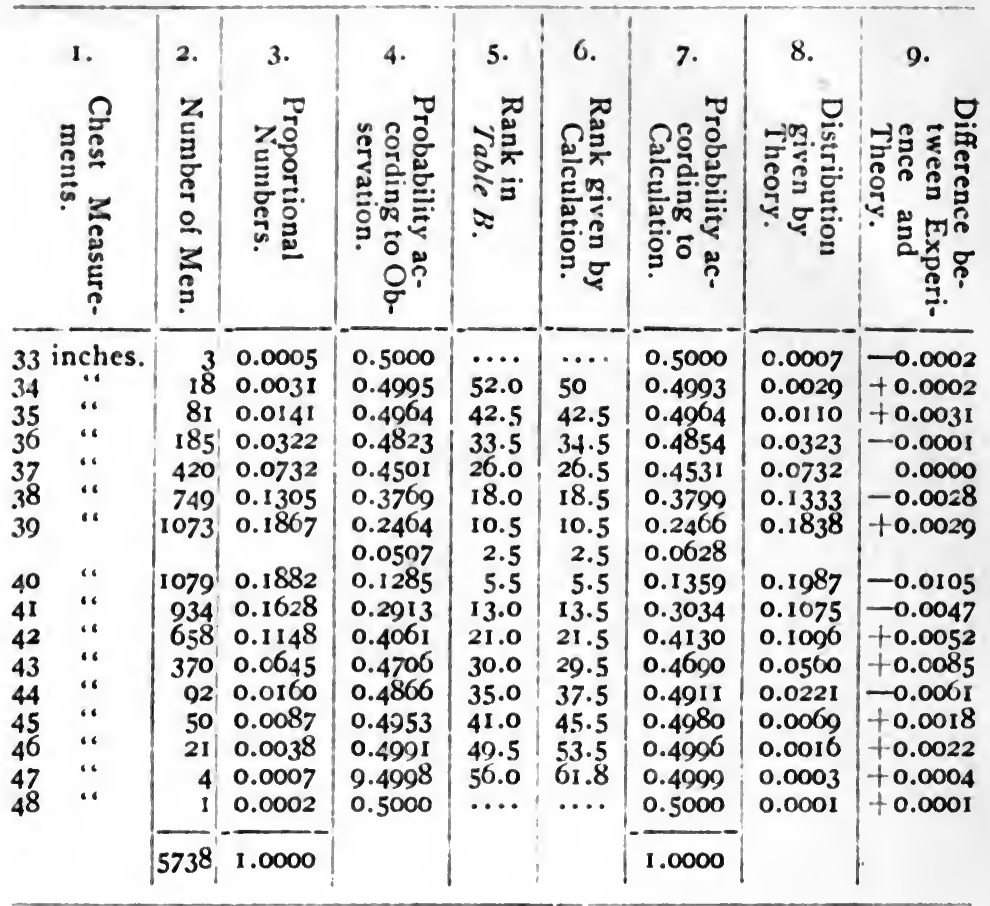

The first column of this table gives the distribution of the units of measurement, in this case inches. The second column gives the frequencies of each group. The third column presents a series of proportional numbers, or the proportion represented by each group frequency when their sum is made equal to unity, the symbol of certainty. The process followed is to divide the total number of observations into unity, and then to multiply this quotient by each frequency in turn. This column gives in fact the probabilities that a measurement will fall under the corresponding groups noted in column one. The distribution being assumed to be normal or symmetrical, one-half of the total number of 
measurements, or .5000 of the total probabilities should be on either side of the mean. The fourth column shows the probability of not exceeding a given measurement, that is, the total probabilities of all measurements from and including the given measurement to the mean. It thus corresponds to Table $B$ of the probability scale. It is found by working inward toward the mean from either extreme, subtracting from .5000 the successive probabilities given by column three. In the fifth column are given the ranks corresponding to the probabilities given in column four. Table $B$ being used for this purpose. Column five thus gives the actual distribution of the observations in ranks of Quetelet's scale.

In order to find the correspondence between experience and theory the foregoing process is now reversed. From the actual distribution of column five a theoretical distribution is found, column six showing the ranks with a uniform difference between them. By this process the distribution is so "smoothed" that each group covers the same number of ranks. Quetelet does not show how he selected the common difference in smoothing the distribution, though it can be approximated by averaging the differences between the ranks as given in column five. There is doubtless an element of arbitrariness in the choice of this difference. The object being to find the difference which gives the closest fit of the curve to the measurements, the true value can be indefinitely approached by repeated trials. From this sixth column is calculated, by the use of Table $B$, column seven corresponding to column four. The successive differences of column seven, working from the mean outward, give column eight, corresponding to column three. Column eight thus gives the probabilities that a measurement would fall under the respective groups, were they actu- 
ally to occur according to the assumptions of the probability curve. In column nine appear the differences between the numbers of columns three and eight, showing the amount of the misfit for each group.

But "each series of observations has its particular scale of possibility.... The nature of this scale is determined by the number of observations, as also by the more or less precise means employed in making such observations." If the observations are represented graphically by the curve of possibility, this curve contracts towards its axis in the ratio of the increase in the square root of the number of observations. ${ }^{2}$ But assuming the observations to be equally numerous, "the contraction towards the axis is proportional to the degree of precision of the observers, and gives a measure of that precision. Our aim then should be to seek means of appreciating the contraction of the curve." 3 Such a means is found in the probable error. As its name implies this is that error or deviation from the mean which is as often exceeded as not exceeded. It thus designates the limits between which one-half of all the observations fall, or the divergence either side of the mean between which and the mean one-fourth of the observations are found.' Since Table $B$ of Quetelet's scale gives the sum of the probabilities on either side of the mean, it is only necessary to locate the value .2500 in this Table in order to determine the rank of the probable error. The precision for rank io is .236548 , and for rank II it is $.256791 .{ }^{5}$ Interpolating, one gets 10.6645 as the rank of the probable error. ${ }^{6}$ The number of ranks included between the

\footnotetext{
'Letlers, p. $77 . \quad$ 'Ibid., "Letter xvi." 'Ibid., p. 80.

“"Sur l'appréciation, ctc.," p. $257 . \quad$ 'See p. 114, supra.
}

"Quetclet commonly speaks of this rank as "about 10.5;" "Sur l'appréciation, elc.," p. 257. In the Letters he gives the rank as 10.67 on p. 271 , and as " nearly 10.66 " on p. 274. 
positive and negative limits of the probable error would therefore be twice 10.6645 or 21.3390 ; Quetelet usually considered 21 ranks as sufficiently near the true value.

Assuming that the distribution should be norma!, Quetelet calculated the probable error from the smoothed data. Having determined the best uniform difference between the ranks as given in column six,' he divides this number into 21 and multiplies the quotient by the dimension of a group as given in column one. This gives him in concrete units the distance between the two limits of probable error. One-half of this distance gives the probable error. A comparison of the probable errors of two sets of measurements of the same thing he considered a measure of their relative precision.'

In the notes of the Lellers Quetelet calculates the odds of not exceeding various sizes of the probable error. This is done easily from Table $B$. Thus twice the probable error is 21.34 ranks. The precision for this rank is .411463 , that is, .411463 out of .5000 of the probabilities lie between twice the probable error and the mean, while $.500000-.411463$ or .088537 of them lie beyond this limit. The ratio of .411463 to .088537 is $4.64: 1$. Similarly the odds in favor of three or more times the probable error may be calculated.3 Quetelet also gives ‘ the relation of the probable error to the standard deviation. He, however, does not seem to have made any use of the standard deviation, though he says it is a quantity " of great importance."

It has been stated that Quetelet assumed the distribu-

'See p. 122, swpra.

'Letlers, p. 82.

'Quetelet's method is somewhat more cumbrous though it gives similar results; Letlers, p. 270, et seg.

- Joid., p. 272, et seg. 
tion of the errors of a set of measurements to be symmetrical. This same assumption, extended to the variations in nature, gave a type about which the variations were evenly distributed. Thus his mean in theory became not only an arithmetic average but also the median and the mode.' It was on this basis that Quetelet viewed the degree of misfit of the measurements to the scale of possibility as a test of the degree of accuracy with which the measurements were made. ${ }^{2}$ It would seem to be quite as plausible to consider the degree of misfit as a test of the accuracy with which the assumptions underlying the theoretical law of normal distribution can be applied to a particular set of observations. While we cannot, as the basis for a theory of the distribution, find any less arbitrary assumptions than that the causes of variation are infinite, minute and equal and that they are equally favorable to excess and deficiency, ${ }^{3}$ yet it strains our credulity to believe that these assumptions must always be true to experience, especially in measurements of mass phenomena. In fact a perfect realization of these assumptions in experience would seem to be fortuitous, and deviations from the perfectly symmetrical distribution may vary through many degrees of asymmetry. The normal curve is thus to be viewed as a form of the distribution of variable objects in nature, approximately realized in some classes of phenomena, but as only one of the many possible forms.

Of this Quetelet seems to have been quite aware. For while in his illustrations he always assumed the normal

'Bowley, op. cit., p. 119, apparently does not consider Quetelet's average as the median and the mode. It is impossible to see how this conclusion can be reached.

2"Sur l'appréciation, etc.," p. 272.

'See Jevons, op. cit., pp. 255 and 380. 
distribution, he was fully aware of asymmetrical distribution and gave a satisfactory explanation of it.' He even contemplated part authorship of a treatment of such cases." Quetelet explained the variations in nature not only by the various combinations of an infinite number of independent and minute causes, but also by the different "degrees of intensity of which these causes are susceptible.", When therefore variations in one direction are found to exceed those in the other, it is due to the causes operating in one direction having "much more probability than the contrary causes, either because they are more numerous or because they are more energetic." When the observations are numerous, the skewness of their distribution becomes an indication of one or more causes more or less powerful, peculiarly favorable to variation in one direction. The normal distribution being viewed as natural, skewness requires special explanation. ${ }^{5}$

It should be noted that while Quetelet gave very great importance to the determination of the average, and the probable deviation from the average, he also frequently emphasized the importance of changes in the limits of variation. His reason for this emphasis was his belief that "one of the principal effects of civilization is that it more and more contracts the limits within which the different elements relating to man oscillate." Believing the averages of human qualities to be for the most part stationary, he believed the perfectibility of man would be

'Some discussion of the unsymmetrical distribution as related to the theory of the Average Man was given on p. 8r, et seq.. supre.

$\checkmark$ See Lellers, p. 113.

- Ibid., p. 124.
'Jbid., p. 106.

'Bowley, 0p. cil.. p. 267.

- Sur l'homme, closing section; English translation, pp. $x$ and 108 ; Physigue saciale, vol. ii, p. 428; Dw Systime sacial, p. 252, et seg. 
shown in an ever-increasing equality among men, physically, intellectually and morally, until all approached the state of the Average Man.' His interpretation of the narrowing of the limits of variation was thus very different from the more recent view which finds in such narrowing an evidence of a more intense struggle for existence, of more severe economic competition," or of increased social pressure. ${ }^{3}$

Quetelet used the word "civilization" in the most general sense; its effects were shown in such phenomena as increased political equality, the prevention of famines and the general diffusion of a sufficiency of food, and the spread of knowledge through all classes. We may then note (1) that he centered attention upon the limits of variation from the type rather than upon the standard deviation of the group; it is the latter which shows best the massing of the group about the type, or the conformity to the type; (2) that he did not give an interpretation of restricted variation in terms of biological or sociological causation, nor cloes his statement in any way suggest the process of natural selection or increased environmental or social pressure as the explanation of the narrowed limits; and (3) from the sociological viewpoint social evolution (in order to avoid the term "civilization") seems to have resulted not only in an increased conformity of men to a type of individual capable of coöperation, but also in an increase of liberty, which implies greater freedom of variation. ${ }^{4}$ The interpretation

'For a discussion of Quetelet's confusion on this point see chap. iii, p. 72, et seg., supra.

${ }^{2}$ H. L. Moore, “The Variability of Wages," Political Science Quarterly, March, 1907.

${ }^{3}$ F. H. Giddings, "'The Measurement of Social Pressure," Quarterly Publications of the American Statistical Association, March, 1908.

-Giddings, Sociology, a lecture delivered at Columbia University in 
of a statistical fact which Quetelet readily found in " one of the effects of civilization," is thus seen to be, sociologically, a difficult problem in balancing the effects of opposing and complex processes and conditions.

It remains to note Quetelet's classification of causes and his method of studying them. For besides making possible a more accurate description of social facts, Quetelet's principle of studying groups rather than individuals opened the way for the study of the causal relation among mass phenomena. Having described a group by means of the average and an index of variability, changes in these constants may be related to changes in the group conditions, that is, to causes sufficiently general to affect the whole or a large part of the group. The method itself thus suggests a classification of causes.

As to their manner of action, Quetelet classified causes as constant, variable or accidental.' He says :

Constant causes are those which act in a continuous manner, with the same intensity and in the same direction. Variable causes act in a continuous manner. with energies and tendencies which change. . . Among variable causes it is above all important to distinguish such as are of a prriodic character, as for instance the seasons. Accideculal causes oniy manifest themselves fortuitously ${ }^{3}$ and act indificrently in any direction."

the Series on Science, Philosophy and Art. February 2t. 1908. p. 34. A sop., especially pp. 39-40.

'Sur l'homme. bk. iv, chap. ii; English translation, p. 103: "Sur l'apprétiation, elc.." p. 207; Letlers, p. 107.

In Dw Systime social, pp. 305-306, he explains that he does not mean that any cause is really accidental. In using the term he merely follows eatablished usage. The accidental causes are themselves necessary results of their antecedents, but are called accidental because we cannot trace these antecedents.

d.ctiens. 1. 10\%. 
Among constant causes Quetelet named sex, age, profession, season, latitude and economic and religious institutions. In the first place it may be noted that Quetelet interpreted social phenomena in terms of external and purely formal conditions. To-day we are interested in sex, age, profession as explanatory of social phenomena, only because of their implications with regard to human interests and mental traits. But it should not be overlooked that it is not possible to interpret social phenomena in terms of mental types until these types have been correlated with the external and formal conditions which Quetelet proposed. In the second place it may be doubted whether the above or any other causes are constant according to Quetelet's definition. He himself seems not to have been quite certain that really constant causes could be found.' Finally it should be recalled that Quetelet looked upon the average as the result of constant causes. It seems nearer the truth however to view the average as the final resultant of all causes, remembering that the more numerous the observations the more prominent become the effects of those causes which are most general in their influence. Since causes are appreciated through changes in the averages, perfectly constant causes must remain inscrutable. Our nearest approach to such causes in statistical inquiry will be general causes which are relatively constant.

Variable causes would seem to occupy a larger place in a satisfactory classification of causes than Quetelet gave them. Seasons appear in his discussion among both constant and variable causes. But if phenomena vary as we pass from one season to another, so do they as we pass from one age, sex, profession, or latitude to 
another. It would seem in iact that all causes of social and organic phenomena, considered as mass phenomena. are more or less variable. Accepting the term then as a general characteristic of all such causes, we may find Quetelet's distinction of periodically variable causes highly useful. The seasons of the year and the hours of the day, or the revolution of the earth about the sun and its rotation on its axis, are of immense infuence on organic life and in human affairs.

The theoretical characterization of accidental causes has already been given. In measurements of social and organic phenomena they include two quite different sets of influences. These are first the causes of accidental errors in counting or measuring, as carelessness, lack of skill or variations in the precision of instruments, and secondly the many minute causes of variations in the phenomena themselves resulting in a more or less symmetrical grouping about their average. Thus in ascertaining the average height of a group of men, there would be mingled both the causes of errors of measurement and the causes of differences in the heights themselves. That in both cases the causes are equal and act indifferently in favor of or in opposition to the average result is only a convenient hypothesis to be fully justified in every case only by experience. But the point to be noted here is that the causes of variability though relatively "feeble" and "indirect," are of varying degrees of feebleness and indirectness, depending upon the scope of the investigation. Thus in studying the heights of the men of a nation, the differences in race, age, place of habitation, nourishment, occupation would be merged together in the average. The group studied may how-

'Letsers, p. 130. 
ever be steadily narrowed and each one of these conditions, which in the general study were deemed of minor importance, can be made most prominent. What is a minor cause for a wide group, becomes a general cause for a narrower group. There is of course a limit to this process of narrowing the group, for causes do not act singly, and with a very small group one condition cannot be sufficiently isolated-the number and variability of many small causes make the results too irregular.

It would seem then that in any given group the causes influencing the observations range in extent from the very minute causes affecting individual cases only, through relatively minute causes to those general causes which affect most or all members of the group. It is only the latter which can produce a change in the average. These are the causes whose effects become more pronounced as the observations increase, the effects of all others being at the same time neutralized. We may thus classify all social causes as variable, and as either minute or general in their influence.

Quetelet states that the art in the study of causes is to group the observations "in such a manner that all the causes, except those whose influence we wish to appreciate, may be considered as having acted equally on the members of each group." If then differences in the results are found, they may be attributed to the influence studied. Thus he studied the relation of age, sex, season to the committing of crime by comparing the observations for one age, sex or season with those of another. This is in reality a study of causation through correlation or concomitant variation. With many measurements Quetelet held that accidental (or minor) causes 
may be neglected, and the effects of constant (or general) causes will become prominent. The effects of periodic causes may be studied by comparing parts of a period, as one season with another, and may be avoided by embracing an entire period, as a year.' From this simple and general basis given by Quetelet, the diffcult problem of studying causal relationships has been advanced to a method of quantitatively measuring the correlation of two variable elements throughout their distribution. 


\section{BIBLIOGRAPHICAL NOTE.}

It does not seem necessary to give here a list of Quetelet's statistical publications, owing to the very thorough studies made by Georg Friedrich Knapp and published in Hildebrand's Jahrbücher für Nationalökonomic und Statistik, vol. xvii. Under the general title, "Bericht über die Schriften Quetelets zur Socialstatistik und Anthropologie," Knapp gives first a classification of these writings both by form and by subject matter (p. 167 , et seq.), secondly a statement of their contents, the writings being divided into three chronological periods (p. 342, et seq.) and thirdly a selection of the more important passages for the presentation of Quetelet's views on many topics (p. 427 , et seq.). It is only necessary to refer the interested reader to these studies for bibliographical material. 


\section{VITA}

THE author of this dissertation was born in Willshire, Van Wert County, Ohio, September 27, 1877. After receiving the degree of A. B. from Baker University in 1901, he was principal of the public schools at Waverly, Kansas, for two years. He was enrolled as a graduate student under the Faculty of Political Science of Columbia University during the three years $1903^{-6}$ and during 1907-8. He was Scholar in Sociology 1904-5. and Fellow in Statistics 1905-6. During 1906-7 he was instructor in Economics and Sociology at Clark College, Worcester, Mass. While at Columbia he attended courses given by Professors Giddings, Clark, Seligman, Moore, Seager and Dunning. 



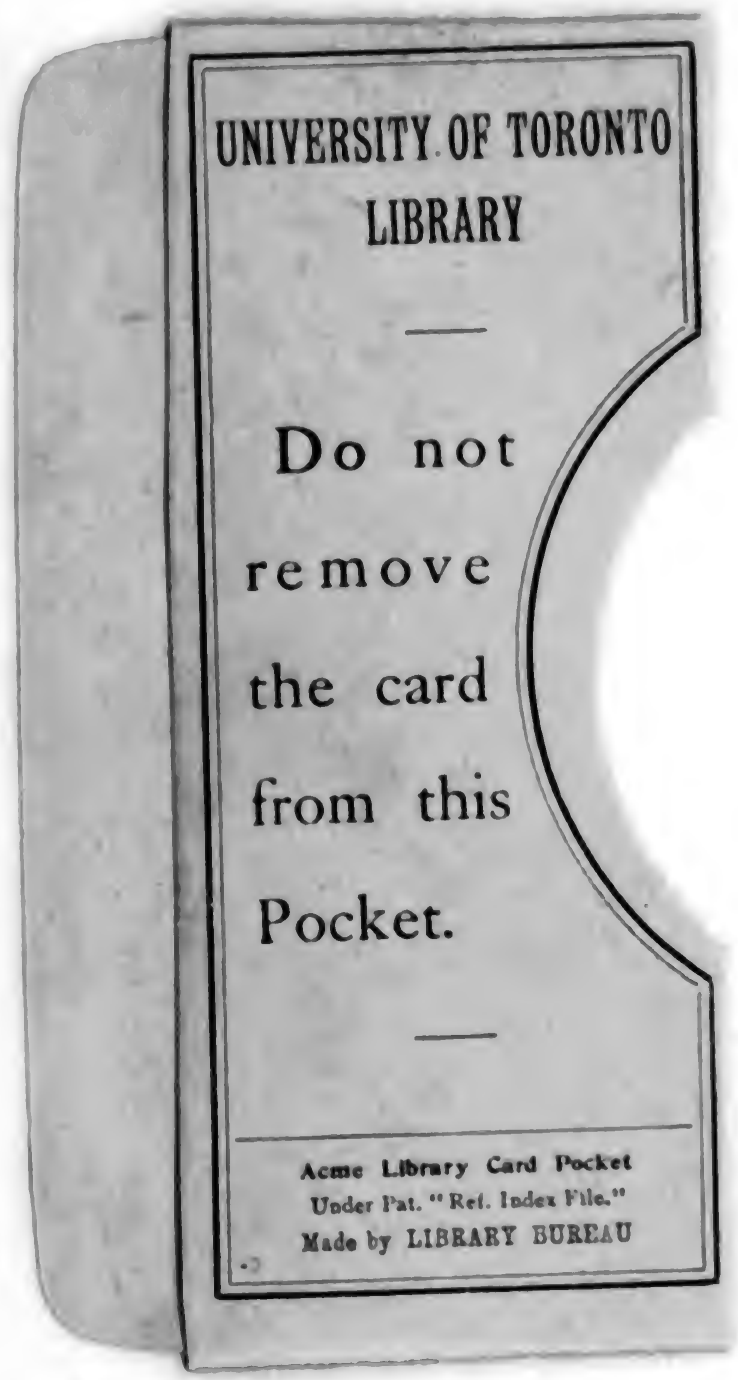


